This is the post-print version of the article:

Ouyang, K., Lam, W., Cheng, B., and Parker, S. K. (2019). "'Enjoy Your Evening, Be Proactive Tomorrow: How Off-Job Experiences Shape Daily Proactivity. Journal of Applied Psychology. The latest version of this article can be found at: https://doi.org/10.1037/ap10000391

Running head: OFF-JOB EXPERIENCES AND DAILY PROACTIVITY

\title{
Enjoy Your Evening, Be Proactive Tomorrow: How Off-Job Experiences Shape Daily Proactivity
}

\author{
Kan OUYANG \\ Department of Human Resource Management \\ Shanghai University of Finance and Economics \\ Shanghai, China \\ E-mail: ouyangkan@mail.shufe.edu.cn \\ Bonnie Hayden CHENG \\ Department of Management and Marketing \\ The Hong Kong Polytechnic University \\ Hung Hom, Kowloon, Hong Kong \\ E-mail: bonnie.cheng@polyu.edu.hk \\ Wing LAM \\ Department of Management and Marketing \\ The Hong Kong Polytechnic University \\ Hung Hom, Kowloon, Hong Kong \\ E-mail: mswing@polyu.edu.hk \\ Sharon K. PARKER \\ Centre for Transformative Work Design \\ Future of Work Institute, Faculty of Business and Law \\ Curtin University \\ Perth, Australia \\ E-mail: s.parker@curtin.edu.au
}

Author note: This research was supported by a grant from the Research Grant Council of the Hong Kong Special Administrative Region, China (GRF 155130) awarded to Wing Lam, Bonnie Hayden Cheng, and Kan Ouyang, a grant from The Hong Kong Polytechnic University Department of Management and Marketing Central Research Grant (G-UADA) awarded to Wing Lam and Bonnie Hayden Cheng, a grant from The Hong Kong Polytechnic University (G-UA6Y) awarded to Bonnie Hayden Cheng, and an Australian Research Council Laureate Fellowship Award awarded to Sharon K. Parker (FL160100033). An earlier version of this article was presented at the 2017 Academy of Management Conference, Atlanta, GA. Correspondence concerning this article should be addressed to Kan Ouyang, College of Business, Shanghai University of Finance and Economics, 100 Wudong Road, Shanghai 2000433, China. E-mail: ouyangkan@mail.shufe.edu.cn 


\title{
Enjoy Your Evening, Be Proactive Tomorrow: How Off-Job Experiences Shape \\ Daily Proactivity
}

\begin{abstract}
Drawing on conservation of resources theory (Hobfoll, 1989) and the model of proactive motivation (Parker, Bindl, \& Strauss, 2010), this research employs experience sampling methods to examine how employees' off-job experiences during the evening relate to their proactive behavior at work the next day. A multilevel path analysis of data from 183 employees across 10 workdays indicated that various types of off-job experiences in the evening had differential effects on daily proactive behavior during the subsequent workday, and the psychological mechanisms underlying these varied relationships were distinct. Specifically, off-job mastery in the evening related positively to next-morning high-activated positive affect and role breadth self-efficacy, off-job agency in the evening related positively to next-morning role breadth self-efficacy and desire for control, and off-job hassles in the evening related negatively to next-morning high-activated positive affect; next-morning highactivated positive affect, role breadth self-efficacy, and desire for control, in turn, predicted next-day proactive behavior. Off-job relaxation in the evening related positively to nextmorning low-activated positive affect, and off-job detachment in the evening had a decreasingly positive curvilinear relationship with next-morning low-activated positive affect. However, as expected, these two types of off-job experiences and low-activated positive affect did not relate to next-day proactive behavior.
\end{abstract}

Keywords: daily proactive behavior, work recovery, positive affect, role breadth self-efficacy, desire for control 
I still need some more healthy rest in order to work at my best. My health is the main capital I have and I want to administer it intelligently.

-Ernest Hemingway

To maintain and replenish personal resources for work, individuals need rest. At the end of their workdays, people often engage in preferred activities to alleviate stress, whether relaxing by reading books or practicing new hobbies, or engaging in activities that distract them from thoughts of work, such as cooking or going to the gym. Such activities and their associated experiences are likely associated with the quality of one's sleep (e.g., Lanaj, Johnson, \& Barnes, 2014), how one feels on waking the next morning (e.g., Sonnentag, Binnewies, \& Mojza, 2008), and even how one performs on the job the next day (e.g., Fritz, Yankelevich, Zarubin, \& Barger, 2010). Although a small number of studies show that off-job experiences predict work outcomes (e.g., Fritz, Yankelevich, et al., 2010; Sonnentag, 2003), little is known about how off-job experiences shape employee proactive behavior at work, a highly desired yet effortful behavior within contemporary organizations.

Employee proactive behavior refers to employee engagement in self-initiated, futureoriented behaviors to take control of situations and create change in the workplace (Grant \& Ashford, 2008; Parker et al., 2010). Such behavior is highly desired by organizations because it enables effective performance in competitive, dynamic, and fast-changing work environments (Bindl \& Parker, 2010; Cangiano \& Parker, 2016). Research consistently demonstrates that proactive behavior has a beneficial impact on employees and organizations, including higher performance evaluations, career success, and more effective organizational performance (e.g., Frese et al., 2007; Grant, Parker, \& Collins, 2009). It is thus important to understand how to facilitate the sustainability of such behavior at work.

Most previous studies of proactive behavior have used a between-person approach to examine its individual (e.g., knowledge, abilities) and situational (e.g., job design, leadership) predictors (Bindl \& Parker, 2010). The problem with this between-person approach is that, 
although it identifies relatively stable sources of variation across individuals, it cannot identify factors that are related to fluctuation in proactive behavior over time. Prior research shows that proactive behavior varies across days, such that the level of each employee's daily proactive behavior regularly changes (Ohly \& Fritz, 2010; Sonnentag, 2003). Employees may display high levels of proactive behavior on some workdays, perhaps actively seeking workrelated feedback from supervisors or introducing new approaches, but they act passively or fail to take initiative on other workdays. Left unaccounted for, such fluctuations might undermine the positive outcomes of proactive behavior. Therefore, we adopt a within-person approach (e.g., Ohly \& Fritz, 2010; Sonnentag, 2003) to focus on daily proactive behavior, in order to provide a more dynamic examination of why proactivity can vary across days.

In particular, two streams of research provide valuable insights into the predictors of daily proactive behavior. The first examines day-level predictors with regard to employees' work experiences. Specifically, researchers found that job control (Ohly \& Fritz, 2010), job stressors such as time pressure (e.g., Sonnentag \& Starzyk, 2015), and employees' daily affective experiences (e.g., Bissing-Olson, Iyer, Fielding, \& Zacher, 2013) relate to daily proactive behavior. The second stream, still in its infancy, investigates the role of employees' experiences after work (i.e., off-job experiences) on their next-day proactive behavior. Three studies (Binnewies, Sonnentag, \& Mojza, 2009; Fritz, Yankelevich, et al., 2010; Sonnentag, 2003) show that employees who feel recovered during their off-job time tend to possess more available resources and thus have a greater tendency to take initiative the next workday. Although existing research provides preliminary evidence that recovery experiences during off-job time positively relate to proactivity, important knowledge gaps remain.

First, most research in the recovery literature draws on a resource perspective to understand how recovery functions. Yet, relying solely on a resource perspective limits our understanding, as the availability of resources does not automatically imply that employees 
will be more proactive. Rather, we argue that the impact on proactive behavior depends on which motivational states are generated as a result of the recovery experiences. In preliminary research, Sonnentag (2003) examined work engagement as a motivational mechanism underlying the relationship between recovery (general positive recovery) and personal initiative, thereby linking recovery, motivation and proactivity. However, this study did not consider how distinct off-job experiences might differentially relate to proactive behavior through their varying effects on motivation. In the current study, we draw upon conservation of resources theory (COR) (Hobfoll, 1989) to consider how off-job experiences predict proactive behavior. We then offer a novel perspective linking off-job experiences and proactive behavior drawing on the model of proactive motivation (Parker et al., 2010). We combine COR and proactive motivation theory to propose that whether and how various offjob experiences are associated with proactive behavior depends on their differential impact on proactive motivation (can do, reason to, and energized to motivations). We also provide needed nuance to the activation element of positive affect, illuminating why only certain types of off-job experiences relate to proactive behavior.

Second, research investigating proactive outcomes has either investigated the effects of employees' general recovery experiences (Binnewies et al., 2009; Sonnentag, 2003) or focused on one specific, positive recovery experience, namely, psychological detachment from work (Fritz, Yankelevich, et al., 2010). Research has not examined other types of recovery experiences, and we know little about whether varying types of recovery experiences relate to proactive behavior and, if so, whether they relate to proactive behavior differently. Grounded in the recovery literature, we evaluate four specific recovery experiences — off-job relaxation, off-job detachment, off-job mastery, and off-job agencywhich represent distinct forms of recovery and together capture key ways that employees recover after work (e.g., Bennett, Gabriel, Calderwood, Dahling, \& Trougakos, 2016; 
Sonnentag \& Fritz, 2007). Drawing on this typology, we theorize and test a more comprehensive view of how different recovery experiences shape daily proactive behavior. Moreover, we extend past work on psychological detachment that has consistently found it to be beneficial (e.g., Sonnentag et al., 2008; Sonnentag \& Fritz, 2007). We propose and test a curvilinear relationship between off-job detachment and next-day low-activated positive affect, theorizing that too much off-job detachment likely ceases to benefit employees.

Third, existing research on daily proactive behavior has focused on positive recovery experiences during off-job time, without noting the potential effect of negative evening experiences, such as hassles, on subsequent proactivity (e.g., Sonnentag et al., 2008; Taris \& Kompier, 2005). Off-job hassles refer to ongoing stressors experienced during off-job time, such as conflicts with family members or additional work demands at home (Bolger, DeLongis, Kessler, \& Schilling, 1989; Lepore \& Evans, 1996), exerting pressure on individuals and draining their resources (Bolger et al., 1989). The only study that links hassles with proactivity found that the more hassles employees experienced during the weekend, the less likely they were to take initiative at the beginning of the coming work week (Fritz \& Sonnentag, 2005). Because negative events tend to have stronger effects than positive events (Baumeister, Bratslavsky, Finkenauer, \& Vohs, 2001), it is important to examine how off-job hassles, as one negative type of off-job experience, predict employee proactivity. We thereby provide a balanced picture of how both positive and negative evening experiences relate to next-day proactive behavior.

\section{Theory and Hypotheses}

Our research model (Figure 1) is grounded in COR theory (Hobfoll, 1989) and the model of proactive motivation (Parker et al., 2010). Taken together, these models provide insights into how various off-job experiences distinctly relate to daily proactivity. COR theory has served as the foundation for guiding past research on recovery from job demands 
(e.g., Binnewies et al., 2009; Sonnentag, 2003; Sonnentag et al., 2008). The theory focuses on the level of resources that are available for individuals at any given moment (Quinn, Spreitzer, \& Lam, 2012), and suggests that individuals are motivated to protect their current resources and acquire new resources. Resources such as time and energy are scarce, yet are consumed when individuals cope with job demands at work (Hobfoll, 1989). It is thus vital to recharge resources after work (Hobfoll \& Shirom, 2001). Using COR theory, the recovery literature has consistently shown that successful recovery during off-job time helps replenish resources and promote individual well-being (for a review, see Demerouti, Bakker, Geurts, \& Taris, 2009). Proactive behavior is resource-intensive, likely consuming and requiring substantial individual resources, as it is discretionary, anticipatory, challenging, and change-oriented, and involves personal initiative, careful planning, complex problem solving, and coping with frustrations and setbacks (e.g., Cangiano \& Parker, 2016; Strauss, Parker, \& O’Shea, 2017). Thus, COR theory provides a useful framework to consider how off-job experiences are associated with recovery and hence, potentially, proactive behavior.

However, off-job experiences and any associated recovery does not in and of itself prompt proactive behavior. Rather, we assert that whether off-job experiences relate to nextday proactivity depends on the motivational state engendered by these experiences. The model of proactive motivation (Parker et al., 2010) suggests that the occurrence of proactive behavior requires a high level of can do, reason to, and energized to motivation to stimulate employees to engage in challenging and risky behavior. Can do motivation refers to individual perceptions that they have the capabilities and opportunities to enact proactive behaviors (Parker, 1998; Parker et al., 2010). One of the most consistently identified can do motivations is role breadth self-efficacy, an individual's perception of being able to carry out a broader and more proactive role than prescribed by technical job requirements (Parker, 1998). Previous studies show that a high level of role breadth self-efficacy enhances 
employees' persistence, effectiveness, and coping capabilities at work and thus relates to more proactive behaviors (e.g., Parker \& Collins, 2010; Parker, Williams, \& Turner, 2006). Our study identifies role breadth self-efficacy as reflecting can do motivation. Reason to motivation involves internal forces that shape employees' initiative to challenge the status quo rather than act passively (Parker et al., 2010). We focus on the desire for control as a manifestation of reason to motivation. Employees' desire for control at work reflects their interest in achieving the explicit goal of gaining control over problems and challenges (Ashford \& Black, 1996). This goal is highly compatible with the nature of proactive behavior, that is, taking control of the situation (Grant \& Ashford, 2008).

Finally, energized to motivation also plays an important role in proactive behavior (e.g., Bindl, Parker, Totterdell, \& Hagger-Johnson, 2012; Fritz \& Sonnentag, 2009; Parker, Collins, \& Grant, 2008). Positive affect can broaden momentary action/thought repertoires and trigger approach action tendencies (Fredrickson, 1998; Isen, 1999), which likely facilitate employees' proactive goal setting and striving at work. Research also distinguishes between low-activated and high-activated positive affect. According to the circumplex model of affect (Russell, 1980, 2003), affect is represented by primitive, momentary feelings that combine the dimensions of valence and activation. Valence reflects an individual's positive versus negative affect, or an evaluation of feeling good or bad about the current state. Activation represents feelings of readiness to engage in energy-demanding actions (Russell, 2003), indicating "motivational intensity" or the "impetus to act" (Gable \& Harmon-Jones, 2010, p. 211). Combining these dimensions results in four distinct quadrants (i.e., high-activated and low-activated positive affect, high-activated and low-activated negative affect ${ }^{1}$ ), each involving discrete affective states and manifesting unique characteristics (Russell, 2003). Low-activated positive affect tends to be related to inactivity and reflection, while high-

\footnotetext{
${ }^{1}$ We do not make predictions for negative affect because the model of proactive motivation (Parker et al., 2010) does not propose negative affect as a motivational state of proactive behavior. Low-activated and high-activated negative affect are treated as control variables in our data analyses.
} 
activated positive affect tends to be related to energy, mobilization, and motivation; they have different predictors and relate to differential action approaches and behavioral outcomes (e.g., Frijda, 1986; Russell, 2003). In our context of employee proactive behavior, considering activation in positive affect is meaningful. Following past research demonstrating that highrather than low-activated positive affect shapes proactive behavior due to its arousal component (Bindl et al., 2012; Parker et al., 2010), we propose high- rather than lowactivated positive affect as a key driver of proactivity. Hence, simply experiencing a sense of recovery per se will not necessarily prompt proactive behavior, since distinct off-job experiences induce different levels of energy activation (Sonnentag \& Fritz, 2007), and will differentially influence can do, reason to, and energized to motivation.

In sum, we propose that whether off-job experiences relate to next-day proactivity depends on the extent to which these experiences predict can do, reason to, and energized to motivation. In the following sections, we first develop arguments as to why off-job mastery and agency relate positively to next-day proactive motivation, whereas off-job hassles relate negatively to next-day proactive motivation. Second, we elaborate how proactive motivation drives proactive behavior, serving as the mechanism that links off-job mastery, agency, and hassles to next-day proactive behavior. Third, we propose that off-job relaxation and detachment are associated with next-morning low-activated positive affect which, although pleasurable, is not expected to predict next-day proactive behavior due to its low arousal.

\section{The Effects of Off-Job Mastery, Off-Job Agency, and Off-Job Hassles on Proactive}

\section{Motivational States}

Off-job mastery. Off-job mastery refers to off-job experiences that include learning or challenging opportunities in off-job domains, such as learning a new language, engaging in sport, or volunteering (Sonnentag \& Fritz, 2007). Mastery challenges individuals without overburdening their abilities (Sonnentag et al., 2008). A sense of competence, proficiency, 
and achievement can be acquired by gains in mastery (Nicholls, 1984; Schwarzer, 1992). Drawing from COR theory, we speculate that mastery experiences help employees recharge and acquire more resources in three ways. First, mastery experiences involve exploring possibilities and learning new skills, which activates physiological, cognitive, or psychological processes (e.g., Phan, 2014; Poldrack, Prabhakaran, Seger, \& Gabrieli, 1999; Sonnentag, 2001). Such activation, together with experiences of need fulfillment, is energizing and uplifts positive affect to a highly-activated level (e.g., Ryan \& Deci, 2008; Sheldon \& Houser-Marko, 2001; Sonnentag et al., 2008). Second, experiences of competency and fulfillment enhance individual self-perceptions of resourcefulness and capability. In fact, competency and satisfaction constitute a category of experiences that encourages selfefficacy (Gist \& Mitchell, 1992). When employees engage in off-job mastery, they tend to perceive themselves as effective and competent and make active attempts to solve problems. At work, this tendency boosts employees' role breadth self-efficacy, or perceived ability to perform proactive activities beyond those prescribed by their jobs (Parker, 1998; Parker et al., 2006). Third, as discussed, mastery-building activities (e.g., learning a new skill) bring about a sense of proficiency and achievement, showing that employees have control over new, difficult, or challenging situations during off-job time (e.g., Bandura, 1997; Sonnentag \& Fritz, 2007). This likely drives employees' desire for control at work because they may have a striving to demonstrate their capabilities and exert influence over their work (e.g., Burger \& Cooper, 1979; Ramsey \& Etcheverry, 2013; Skinner, 1996).

Hypothesis 1: Off-job mastery during evening hours is positively related to (a) highactivated positive affect (energized to motivation), (b) role breadth self-efficacy (can do motivation), and (c) desire for control (reason to motivation) the next morning. Off-job agency. Off-job agency reflects an individual's discretion and ability to organize a schedule of activities during off-job time (Sonnentag \& Fritz, 2007). It creates 
perceptions of personal control, because it involves making decisions about how to spend leisure time. Such an agentic experience of having control over choice of off-job activities fulfills the need for autonomy (Deci \& Ryan, 2000; Trougakos, Hideg, Cheng, \& Beal, 2014), and such feelings in turn energize individuals and engender activated positive states (e.g., joyful, enjoyment, feeling alive; Reis, Sheldon, Gable, Roscoe, \& Ryan, 2000). We thus expect a positive relationship between off-job agency and high-activated positive affect. Moreover, individuals with high levels of personal control are more motivated, persistent, and likely to adopt a proactive action approach, which strengthens the effectiveness of their actions and enhances their belief that they are capable (Liu, Wang, Hui, \& Lee, 2012; Ross \& Broh, 2000). Therefore, similar to off-job mastery, off-job agency generates a sense of competence and fulfillment that strengthens role breadth self-efficacy. Further, off-job agency likely enhances desire for control at work. Studies show that individuals who experience high levels of control in one situation tend to exhibit negative emotional reactions when they lose or lack control in other situations (Ramsey \& Etcheverry, 2013; West \& Rushton, 1989). That is, a sense of agency experienced during off-job time stimulates individuals' desire for control at work, to maintain the desired feelings of autonomy, competence, and achievement.

Hypothesis 2: Off-job agency during evening hours is positively related to (a) highactivated positive affect (energized to motivation), (b) role breadth self-efficacy (can do motivation), and (c) desire for control (reason to motivation) the next morning. Off-job hassles. Off-job hassles, a negative type of off-job experience (e.g., Fritz \& Sonnentag, 2005; Sonnentag et al., 2008), refer to extra stressors encountered after work (Bolger et al., 1989; Lepore \& Evans, 1996). Examples of off-job hassles experienced during evening hours include attending to chores or disciplining children. Such hassles are inevitable and may happen regularly in daily life and pose extra demands. Grounded on COR theory, dealing with hassles consumes personal resources, impedes recovery, and hinders resource 
replenishment during off-job time (Hobfoll, 1989; Hobfoll \& Shirom, 2001). Empirical studies also suggest that hassle experiences deplete physical and emotional resources and relate to outcomes such as strain, exhaustion, low work engagement, and poor job performance (Bolger et al., 1989; Fritz \& Sonnentag, 2005; Taris \& Kompier, 2005). That is, dealing with hassle experiences requires high levels of personal effort and drains employees' limited yet critical resources (e.g., Hobfoll \& Shirom, 2001). This likely entails employees' feeling a loss of control and weakening of their positive evaluation of themselves (e.g., Lazarus, 1991; Zohar, Tzischinski, \& Epstein, 2003), producing a low level of next-morning positive affect in general, including low-activated and high-activated positive affect (e.g., Gallo, Bogart, Vranceanu, \& Matthews, 2005; Mandler, 1984; Peterson, 1999).

Hypothesis 3: Off-job hassles during evening hours are negatively related to (a) lowactivated positive affect and (b) high-activated positive affect (energized to motivation) the next morning.

\section{The Mediating Roles of Proactive Motivational States}

Energized to motivation: High-activated positive affect. High-activated positive affect stimulates the extent to which individuals are prepared to engage in effortful and vigorous actions, thereby enhancing the intensity of the motivation to act (Gable \& HarmonJones, 2010). Specifically, proactive behavior involves using self-initiative, challenging the status quo, and taking control of work situations. High-activated positive affect enhances individuals' willingness to actively invest resources or efforts, due to their energetic and motivational states (Brehm, 1999). In this sense, high-activated positive affect predicts high levels of energy and acts as a driving force, thus motivating employees to engage in proactive actions that require more active efforts (Bindl et al., 2012). Consistently, researchers have found that high- rather than low-activated positive affect relate to self-initiated, risk-taking behaviors (Bindl et al., 2012; Parker et al., 2010). We therefore propose that high-activated 
positive affect fosters employee proactive behavior. Combined with our earlier argument that off-job agency, mastery, and hassles are the experiences that relate to high-activated positive affect, we further predict that high-activated positive affect mediates such relationships. Hypothesis 4: High-activated positive affect in the morning mediates (a) the positive relationship between off-job mastery during evening hours and proactive behavior during the subsequent workday, (b) the positive relationship between off-job agency during evening hours and proactive behavior during the subsequent workday, and (c) the negative relationship between off-job hassles during evening hours and proactive behavior during the subsequent workday.

Can do motivation: Role breadth self-efficacy. Employees with high role breadth self-efficacy perceive themselves as competent initiative-takers who are capable of engaging in proactive activities at work, such as facilitating team interdependence or coordinating among departments (Parker, 1998). Because proactive behavior entails risk taking and challenging behaviors, it is crucial that employees feel confident that they can initiate such behaviors and cope with possible consequences (Parker et al., 2010). Studies consistently show a positive link between role breadth self-efficacy and proactive behavior (e.g., Axtell et al., 2000; Parker et al., 2006); role breadth self-efficacy increases employees' persistence in achieving proactive goals and enhances their readiness to overcome obstacles during the process (Bandura, 1997; Frese \& Fay, 2001). As we have argued, through off-job mastery and agency, employees come to view themselves as resourceful and capable, in that the needs for autonomy and competence are satisfied. A sense of mastery and agency during off-job time not only replenishes resource pools but also develops and strengthens their role breadth selfefficacy. In turn, they are more likely to engage in subsequent proactive behavior at work. Specifically, experiencing a sense of mastery and agency during off-job recovery experiences likely relates to next-day proactive behaviors, due to the increase in role breadth self-efficacy. 
Hypothesis 5: Role breadth self-efficacy in the morning mediates (a) the positive relationship between off-job mastery during evening hours and proactive behavior during the subsequent workday and (b) the positive relationship between off-job agency during evening hours and proactive behavior during the subsequent workday.

Reason to motivation: Desire for control. Desire for control represents the extent to which employees expect and want to exert control over issues at work (Ashford \& Black, 1996; Burger \& Cooper, 1979), such as how to accomplish their job tasks. This desire is consistent with the key characteristics of proactive behavior, that is, taking control of situations and performing change-oriented behaviors (Grant \& Ashford, 2008). Desire for control thus operates as a salient internal force that drives proactivity at work. Those with a high desire for control likely display high aspiration, expect high performance, respond to challenging tasks, and persist at difficult tasks (Burger, 1985). Research has shown that a high desire for control encourages new employees' proactive behaviors, such as job-change negotiation and relationship building (Ashford \& Black, 1996). Although desire for control has traditionally been examined as a trait or individual difference variable, there is evidence that it is malleable and can be temporarily enhanced or subdued (Ramsey \& Etcheverry, 2013). Based on our hypotheses of positive links between off-job mastery, agency, and desire for control, we expect that desire for control mediates these positive relationships.

Hypothesis 6: Desire for control in the morning mediates (a) the positive relationship between off-job mastery during evening hours and proactive behavior during the subsequent workday and (b) the positive relationship between off-job agency during evening hours and proactive behavior during the subsequent workday.

\section{Off-Job Experiences Unrelated to Proactive Behavior}

Since our study aims to provide a comprehensive picture of the effects of varying types of off-job experiences on daily proactivity, we also consider off-job relaxation and off- 
job detachment following prior research (e.g., Bennett et al., 2016; Sonnentag et al., 2008; Sonnentag \& Fritz, 2007). Off-job relaxation and off-job detachment are not likely associated with next-day proactive behavior by virtue of their lack of effect on proactive motivation, but these two types of off-job experiences are important for pleasurable low activation states.

Off-job relaxation. Relaxation is a process that decreases sympathetic activation (e.g., heart rate, muscle tension) and involves little individual effort or expenditure of resources (Benson, 1975). Physical and mental relaxation can be achieved through various activities, including meditation (Grossman, Niemann, Schmidt, \& Walach, 2004), progressive muscle relaxation (Jacobson, 1938), or listening to music (Pelletier, 2004). Experiencing physical and mental relaxation facilitates individuals' functioning to return to prestressor levels (Meijman \& Mulder, 1998). Based on COR theory, such positive experiences help individuals build personal resources. Empirical studies also show that relaxation helps reduce tension and other symptoms of poor well-being (Stone, Kennedy-Moore, \& Neale, 1995; Van der Klink, Blonk, Schene, \& Van Dijk, 2001). Positive affect accordingly increases after relaxation experiences (e.g., Fredrickson, 2000; Stone et al, 1995).

Specifically, using a resource perspective, Sonnentag et al. (2008) found that off-job relaxation enhanced next-morning serenity (low activation positive affect) rather than activated positive affect, suggesting that the activation level of positive affect corresponds with the activation level of recovery experiences. It is noteworthy that off-job experiences likely unfold in varying ways when different time frames (e.g., weekdays and weekends) are adopted (e.g., Binnewies, Sonnentag, \& Mojza, 2010; Fritz, Sonnentag, Spector, \& McInroe, 2010). For example, Fritz, Sonnentag, et al. (2010) found that weekend relaxation predicts both serenity and joviality during the following work week. Since our study focuses on the next-day effect of off-job experiences, we align with the arguments of previous studies that employ the same time frame that the activation level of recovery experiences predicts the 
activation level of positive affect (e.g., Sonnentag et al., 2008). Therefore, we hypothesize that off-job relaxation during evening hours is positively associated with low- rather than high-activated positive affect the next morning, because relaxation is associated with low levels of activation, such as decreased sympathetic activation and energy expenditure.

Hypothesis 7: Off-job relaxation during evening hours is positively related to lowactivated positive affect the next morning.

Off-job detachment. Off-job detachment refers to physically and mentally distancing from work or thoughts of work (Etzion, Eden, \& Lapidot, 1998). When psychologically detached from work, employees stop thinking or ruminating about job-related problems and gain distance from negative events that might induce fatigue and negative affect. According to COR theory, detachment from work helps remove work demands and restore depleted psychological resources (Hobfoll, 1989, 1998). Moreover, as discussed in Fritz, Sonnentag, et al. (2010), detachment on weekdays primarily denotes forgetting about work temporarily, whereas detachment on weekends likely involves engaging in pleasurable activities. Hence, according to COR theory, off-job detachment on weekdays likely relates to a low level of activation because it leaves out work-related stressful and demanding events (e.g., Brosschot, Gerin, \& Thayer, 2006; Sonnentag et al., 2008), suggesting an overall positive relationship between off-job detachment on weekdays and next-morning low-activated positive affect.

Further, in accordance with Fritz, Yankelevich, et al. (2010) and Bennett et al. (2016), we propose that this positive relationship tapers off at high levels of off-job detachment. A high level of detachment is associated with high psychological and physical distance from work. This detached mindset may carry forward to the next morning, after returning to work. Starting the workday with an excessively detached mindset may require employees to exhibit substantial self-regulation to be able to switch into a work role mindset. Such reattachment to work, a process of reestablishing a mental connection with work, likely involves reflective 
thoughts about, or deliberate planning of, the upcoming workday (Sonnentag \& Kühnel, 2016). The sudden transition from low activation to concentrated effort, as is necessary to direct attention to work, focus on job tasks, and intentionally return to working mode, requires substantial personal resources, which may impair low-activated positive affect.

Hypothesis 8: There is a curvilinear relationship between off-job detachment during evening hours and low-activated positive affect the next morning, such that the overall positive relationship is attenuated at higher levels of off-job detachment.

\section{Method}

\section{Participants and Procedure}

Our sample comprised 183 full-time employees from a range of IT and telecommunication organizations in China. Participants came from different occupations, including engineers, data analysts, and human resource specialists. Of the 183 participants, $46.4 \%$ were women, and $86.8 \%$ had obtained at least a college degree. The average age was 26.1 years $(S D=5.02)$. Participants' average organizational tenure was 1.1 years $(S D=1.96)$, and their average working time was 45.9 hours per week $(S D=12.30)$.

To recruit participants, we approached several IT and telecommunication organizations, and, upon obtaining consent from their top management, sent emails to invite employees to participate ${ }^{2}$. The invitation contained a brief explanation of the purposes of the study and instructions on how to complete the survey. In these emails, we also offered an incentive of RMB300 (approximately US\$43) to each participant who completed all the questionnaires during the course of our study ( 3 times a day $\times 10$ workdays).

We adopted an experience sampling methodology (ESM) and collected data through online surveys, sending emails to participants with website links containing the corresponding questionnaires. All questionnaires were conducted in Chinese. We followed

\footnotetext{
${ }^{2}$ Human subjects ethical review and approval for the study was granted by The Hong Kong Polytechnic University (Protocol No. HSEARS20151230005; Title: Enjoy Your Night, Stay Proactive Tomorrow: Exploring the Motivational Mechanisms of Off-Job Experiences-Proactive Behavior Relationships).
} 
best practices for translation-back translation procedures (Brislin, Lonner, \& Thorndike, 1973) to translate the scales that were originally developed in English. We asked participants to complete one general survey that assessed their dispositional and demographic characteristics before commencing the daily surveys. Then, one week after the general survey, we sent three surveys per day for ten consecutive workdays. To increase the participation rate, we sent participants several email reminders of the detailed schedule for the surveys. The three daily surveys were sent at corresponding time points during the workday. Specifically, we sent the first daily survey in the morning (i.e., 9:00 a.m.). We asked employees to assess their feelings and state at the beginning of the workday. The morning survey rated low-activated and highactivated positive affect (energized to motivation), role breadth self-efficacy (can do motivation), and desire for control (reason to motivation). We also assessed low-activated and high-activated negative affect and treated them as control variables. In the second daily survey, sent in the late afternoon (i.e., 4:30 p.m.), proactive behavior at work that day was assessed. Participants received the third daily survey in the evening (i.e., 9:00 p.m.); we measured employees' off-job experiences and asked them to complete the survey before going to bed. Participants were instructed to fill in the morning and end-of-workday surveys within one hour after receiving the e-mail with the study link. For the evening survey, we excluded responses that were answered after 11:59 p.m. On average, participants completed morning surveys at 9:24 a.m. ( $S D=0.21$ hour), end-of-workday surveys at 5:08 p.m. ( $S D=$ 0.31 hour), and evening surveys at 10:29 p.m. ( $S D=1.12$ hour).

In total, 198 participants signed up for our study. The general survey was completed by 196 of these people. Out of the 196 participants, 192 provided 1683 morning data sets, 1663 end-of-workday data sets, and 1656 evening data sets. We deleted 47 morning surveys, 61 end-of-workday surveys, and 32 evening surveys that had not been answered within the requested time period, leaving 1636 valid morning surveys, 1602 valid end-of-workday 
surveys, and 1624 valid evening surveys. As a result, 183 participants provided valid daylevel data on a total of 1597 days, out of a maximum of $1960(196 \times 10)$, for a response rate of $81.5 \%$. In the next step, we matched the morning data with the end-of-workday data of the same day and the evening data of the previous day; this combination represented one full day-level data point. We followed Singer and Willett's (2003) procedure to include in the final sample only respondents who had provided at least three completed daily data points. This step resulted in our final data set of 1240 matched daily responses from 183 individuals.

\section{Daily (Within-Individual) Measures: Evening Survey}

We measured off-job experiences by asking employees to indicate the extent to which they engaged in the listed experiences "tonight." We used the 12-item scale from the Work Recovery Experience Questionnaire (Sonnentag \& Fritz, 2007) to assess off-job relaxation (4 items), off-job detachment (4 items), off-job mastery (4 items), and off-job agency (4 items). An example for off-job relaxation was "I used the time to relax" (within-person $\alpha=.93$, between-person $\alpha=.98^{3}$ ); a sample item for off-job detachment was "I forgot about work" (within-person $\alpha=.90$, between-person $\alpha=.97$ ); an example item for off-job mastery was "I learnt new things" (within-person $\alpha=.82$, between-person $\alpha=.98$ ); a sample item for off-job agency was "I determined for myself how I would spend my time" (within-person $\alpha=.89$, between-person $\alpha=.98$ ). We assessed off-job hassles with a 9-item scale adapted from the measure developed by Bolger and colleagues (1989). A sample item was "I had an argument with my spouse" (within-person $\alpha=.75$, between-person $\alpha=.88$ ). All these measures used a 7-point Likert response scale ranging from 1 (not at all) to 7 (to a great extent).

\section{Daily (Within-Individual) Measures: Morning Survey}

Low-activated and high-activated positive affect (energized to motivation). We assessed low-activated and high-activated positive affect using an 8-item scale from Warr

\footnotetext{
${ }^{3}$ The within-person and between-person $\alpha$ of our daily scales were calculated using the Mplus code from Geldhof, Preacher, and Zyphur (2014).
} 
(1990). We asked employees to rate the extent to which they experienced the listed emotions "so far today" $(1=$ not at all to 7 = to a great extent). Specifically, 4 items (i.e., "at ease", "calm", "laid-back", and "relaxed") were used to assess low-activated positive affect (withinperson $\alpha=.82$, between-person $\alpha=.95$ ); 4 items (i.e., "enthusiastic", "excited", "inspired", and "joyful") were used to assess high-activated positive affect (within-person $\alpha=.90$, between-person $\alpha=.96)$.

Role breadth self-efficacy (can do motivation). We assessed role breadth selfefficacy using a 3-item scale adopted from Parker (1998). We asked employees how confident they felt "right now" carrying out a range of tasks. The three items were “presenting information to a group of colleagues", “designing new procedures for my work area", and "helping to set targets in my area" $(1=$ not confident at all to $7=$ very confident; within-person $\alpha=.79$, between-person $\alpha=.95)$.

Desire for control (reason to motivation). We assessed desire for control using a 3item scale by Ashford and Black (1996). We asked employees to rate how much control they would like to have over the listed issues related to their work "right now", using the stem "Right now, I would like to have control over...". The three issues were “... variety of tasks", “... performance standards in my work unit”, and “... when things will get done in my work unit" $(1=$ no control at all to $7=$ extreme control; within-person $\alpha=.77$, between-person $\alpha$ $=.87)$.

\section{Daily (Within-Individual) Measures: End-of-Workday Survey}

We measured employees' daily proactive behavior at the end of the workday using a 9-item scale developed by Griffin and colleagues (2007). Employees reported the extent to which they had engaged in the listed behaviors "during the workday today." Sample items included "initiated better ways of doing my core tasks" and "improved the way my work unit did things" $(1=$ not at all to $7=$ very frequently; within-person $\alpha=.87$, between-person $\alpha$ 
$=.98)$.

\section{Control Variables}

We controlled for employees' proactive personality, because it positively predicts proactive behaviors (e.g., Parker et al., 2006); moreover, it may relate more to some off-job experiences (e.g., mastery) than others. ${ }^{4} \mathrm{We}$ assessed proactive personality in the general survey using a 10-item scale developed by Bateman and Crant (1993). An example item was "I am constantly on the lookout for new ways to improve my life" ( $1=$ strongly disagree to 7 $=$ strongly agree $; \alpha=.83)$. We also controlled for negative affect, as positive and negative affect are suggested to be modeled simultaneously as they may relate to one another (Watson, Wiese, Vaidya, \& Tellegen, 1999). We included an 8-item scale from Warr (1990) of lowactivated and high-activated negative affect in the morning survey as two controls in our data analyses. For instance, items for low-activated negative affect included "depressed" and "hopeless" (within-person $\alpha=.89$, between-person $\alpha=.98$ ). Items for high-activated negative affect included "anxious" and "nervous" (within-person $\alpha=.90$, between-person $\alpha=.98$ ). Moreover, we controlled for participants' proactive behavior during the previous workday, as previous-day proactive behavior likely acts as positive and motivating experiences at work that may boost individuals' next-day role breadth self-efficacy and desire for control (Bandura, 1997; Cangiano \& Parker, 2016).

\section{Analytical Approach}

Because our study used a nested research design, such that data from multiple days were nested within employees, we conducted a multilevel path analysis with Mplus 7.4 to test our hypotheses. This approach allows for simultaneous estimation of the paths in our proposed model. Specifically, the within-individual variables in Figure 1 were modeled at Level 1 using random slopes. For control variables, within-individual controls (morning low-

\footnotetext{
${ }^{4}$ Employee demographics (i.e., age, gender, and organizational tenure) were not significantly correlated with low- and highactivated positive affect, role breath self-efficacy, desire for control, and proactive behavior and were thus excluded from the data analyses. Including these variables as control variables in the analyses did not change the results.
} 
and high-activated negative affect, previous-day proactive behavior) were modeled at Level 1 with fixed slopes and the between-individual control (proactive personality) was modeled at Level 2. In line with methodological recommendations regarding daily-level data nested within individuals (e.g., Enders \& Tofighi, 2007; Hofmann, Griffin, \& Gavin, 2000), we centered all Level 1 predictors and control variables around the individual (i.e., group-mean centering) and Level 2 control variables at the grand mean. Further, we employed a parametric bootstrap to estimate the significance of the mediating effects and then obtained confidence intervals based on Monte Carlo simulations with 20,000 replications (e.g., Preacher, Zyphur, \& Zhang, 2010; Selig \& Preacher, 2008).

\section{Results}

\section{Preliminary Analyses}

Table 1 presents the proportion of within-individual variance in each daily variable in our study. The daily measured constructs displayed considerable variance at the day level, ranging from $34 \%$ to $64 \%$. Therefore, it is appropriate to utilize within-person modeling for data analysis. Table 2 presents the means, standard deviations, and correlations of the study variables. To provide support for the discriminant validity of the key self-reported constructs in our study, we conducted within-individual confirmatory factor analyses. Specifically, we included the ten variables in the model (see Figure 1). The 10-factor model exhibited a good

fit to the data, $\chi^{2}(1035)=1821.76, \mathrm{CFI}=.92, \mathrm{RMSEA}=.06$. Further, this model fit the data better than alternative models, which supports the discriminant validity of these variables.

\section{Hypothesis Testing}

Table 3 shows the parameter estimates of the multilevel path analysis. We also summarize the key results in Figure 2. Notably, the four controls (i.e., proactive personality, morning low- and high-activated negative affect, previous-day proactive behavior) were significantly associated with morning low- and high-activated positive affect, morning role 
breadth self-efficacy, morning desire for control, and day-level proactive behavior; controlling for their effects thus allows for a more robust test of the hypotheses. As shown in Table 3, previous-evening off-job mastery related to higher levels of morning high-activated positive affect $(\gamma=.06, p<.05)$ and role breadth self-efficacy $(\gamma=.07, p<.05)$, but its effect on desire for control was non-significant $(\gamma=.04, n s)$, in support of Hypotheses $1 \mathrm{a}$ and $1 \mathrm{~b}$ but not Hypothesis 1c. Regarding the effects of previous-evening off-job agency, it predicted employee's morning role breadth self-efficacy $(\gamma=.09, p<.01)$ and desire for control $(\gamma$ $=.08, p<.01)$ but not high-activated positive affect $(\gamma=.03, n s)$, supporting Hypotheses $2 \mathrm{~b}$ and 2c but not Hypothesis 2a. Previous-evening off-job hassles predicted lower levels of morning high-activated $(\gamma=-.09, p<.01)$ but not low-activated positive affect $(\gamma=-.01, n s)$, supporting Hypothesis $3 \mathrm{~b}$ but not Hypothesis $3 \mathrm{a}$.

Table 3 further shows that all three mediators related significantly to daily proactive behavior $\left(\gamma_{\text {high-activated positive affect }}=.08, p<.01 ; \gamma_{\text {role breadth self-efficacy }}=.09, p<.01 ; \gamma_{\text {desire for control }}\right.$ $=.11, p<.01)$. We then tested the mediation hypotheses (Hypotheses $4-6)$ following the recommendations of Preacher et al. (2010) and Selig and Preacher (2008). It is noteworthy that because the off-job agency-high-activated positive affect linkage and off-job masterydesire for control linkage were non-significant, we did not test the associated mediation hypotheses (i.e., H4b and H6a), in the process failing to support Hypotheses $4 \mathrm{~b}$ and $6 \mathrm{a}$. Specifically, the indirect effects of previous-evening off-job mastery and off-job hassles on daily proactive behavior through morning high-activated positive affect were .005 [95\% CI: $(.001, .014)]$ and -.007 [95\% CI: (-.019, -.001)], respectively, in support of Hypotheses 4a and 4c. The indirect effects of previous-evening off-job mastery and off-job agency on daily proactive behavior through morning role breadth self-efficacy were .006 [95\% CI: $(.002, .014)]$ and .008 [95\% CI: $(.003, .015)]$, respectively, in line with Hypotheses 5a and 5b. The indirect effect of previous-evening off-job agency on daily proactive behavior through 
morning desire for control was .009 [95\% CI: (.003, .018)], supporting Hypothesis 6b. Our results thus demonstrate that employees' motivational states in the morning before workhigh-activated positive affect, role breadth self-efficacy, and desire for control—differentially mediate the effects of previous-evening off-job mastery, off-job agency, and off-job hassles on daily proactive behavior.

We also ran a multilevel path analysis of the model that adds a path from morning low-activated positive affect to daily proactive behavior on the basis of our proposed model. The effect of morning low-activated positive affect on daily proactive behavior was nonsignificant $(\gamma=.01, n s)$, and the remaining results were essentially the same as presented in Table 3. As predicted, morning high-activated rather than low-activated positive affect contributed to a higher level of daily proactive behavior.

Additionally, as shown in Table 3, previous-evening off-job relaxation was positively related to morning low-activated positive affect $(\gamma=.11, p<.01)$, in support of Hypothesis 7 . Table 3 shows that the squared term of previous-evening off-job detachment was significantly related to morning low-activated positive affect $(\gamma=-.03, p<.05)$. Following Aiken and West (1991), we conducted simple slope tests to confirm the shape of the curve. When off-job detachment was low (one $S D$ below the mean), the simple slope of the regression curve had a significant and positive value $(\beta=.16, p<.01)$; when off-job detachment was high (one $S D$ above the mean), the simple slope was non-significant $(\beta=.07, n s)$. The results suggest a decreasingly positive curvilinear relationship between previous-evening off-job detachment and morning low-activated positive affect, supporting Hypothesis 8. We plotted the curvilinear relationship in Figure 3.

\section{Supplemental Analyses}

Due to the nature of ESM data, time-series trends may exist (Beal \& Weiss, 2003). We used three variables, that is, day, sine, and cosine, to model the linear and cyclical trends of 
our data (Beal \& Weiss, 2003; West \& Hepworth, 1991). Multilevel analysis shows that these three time-based factors did not significantly relate to the key outcome variables of our study, indicating that trends and cycles were not an issue in our data. We also explored whether daily proactive behavior relates to off-job experiences in the evening. The multilevel analysis results show that daily proactivity was not associated with off-job experiences in a meaningful way, which, to some extent, provides some evidence of causality of our study ${ }^{5}$.

\section{Discussion}

Just as Hemingway pointed to the need to manage healthy rest intelligently, our research reveals that how employees enjoy their evening predicts whether they will be proactive the next day. Specifically, based on day-level data, we found that off-job mastery was positively associated with high-activated positive affect (energized to motivation) and role breadth self-efficacy (can do motivation), off-job agency was positively associated with role breadth self-efficacy (can do motivation) and desire for control (reason to motivation), and off-job hassles was negatively associated with high-activated positive affect (energized to motivation); high-activated positive affect (energized to motivation), role breadth selfefficacy (can do motivation), and desire for control (reason to motivation), in turn, predicted proactive behavior. Moreover, off-job relaxation related positively to low-activated positive affect, and off-job detachment had a decreasingly positive curvilinear relationship with lowactivated positive affect; however, low-activated positive affect did not relate to proactive behavior. Taken together, our findings demonstrate that these five types of off-job experiences exert varying effects on proactive behavior, through unique mechanisms.

\section{Theoretical Implications}

Our research contributes to the existing literature in several ways. At a global level, our study contributes to the literature on work recovery and, more broadly, employee off-job

\footnotetext{
${ }^{5}$ The results of these two supplemental analyses are available from the authors upon request.
} 
experiences by adopting a motivation perspective. Previous studies on recovery primarily used a resource perspective; however, this approach can restrict our understanding of how off-job experiences shape proactive behavior, as the occurrence of proactive behavior requires an individual's intense and active motivational state yet resource replenishment does not always induce such states. Grounded in the model of proactive motivation, our findings indicate that off-job experiences that provide employees with relevant motivational resources to use at work are beneficial for increasing employee proactive behavior. By integrating proactive motivation theory with the recovery literature, we test a motivation framework of how off-job experiences in the evening relate to next-day proactive behavior through motivational states. Bringing a novel motivation perspective to off-job experiences, we illuminate why only some types of off-job experiences enhance employee proactivity.

Our findings show that not all off-job experiences relate to daily proactive behavior. Specifically, off-job mastery enhances can do (i.e., role breadth self-efficacy) and energized to (i.e., high-activated positive affect) proactive motivations, off-job agency promotes the proactive motivations of can do (i.e., role breadth self-efficacy) and reason to (i.e., desire for control), while off-job hassles undermine energized to motivation (i.e., high-activated positive affect). In contrast, off-job relaxation exhibits a linear relationship, and off-job detachment a curvilinear relationship, with low-activated positive affect, neither of which motivates proactive behavior. It is intriguing that too much detachment from work during the evening does not help employees. On the basis of previous research (e.g., Bennett et al., 2016; Sonnentag \& Kühnel, 2016), we propose and find that when employees mentally distance themselves too much from thoughts of work in the evening, employees are more likely to experience difficulty transitioning from a detached mindset back to working mode when returning to work the next day, thereby weakening next-morning low-activated positive affect. We thus extend research on psychological detachment that shows detachment is beneficial 
(e.g., Sonnentag et al., 2008; Sonnentag \& Fritz, 2007). Additionally, the results associated with off-job mastery and off-job relaxation correspond to Sonnentag et al.'s (2008) findings, suggesting that off-job experiences that stabilize individual functional systems and induce inactivity are insufficient for increasing employee proactive behavior. Furthermore, regarding our non-significant findings for the linkages of off-job mastery-desire for control (H1c) and off-job agency-high-activated positive affect (H2a), it is important to observe that there are significant, positive within-person correlations between these variables (see Table 2). We also conducted additional multilevel analyses using only off-job mastery to predict desire for control $(\gamma=.07, p<.05)$ and only off-job agency to predict high-activated positive affect $(\gamma$ $=.06, p<.05)$; the results are consistent with our hypotheses. However, when included in the full model, the two paths were non-significant, suggesting that these paths are not unique contributors over and above other significant paths. We recognize that examining multiple off-job experiences and motivational states in one model is a rather stringent test, and further studies are needed to replicate our findings. Moreover, we found that off-job hassles only predicted high-activated not low-activated positive affect. One possible explanation is that off-job hassles have an impact on the activation dimension of affect, that is, experiencing hassles during off-job time is associated with individuals' readiness for action (Russell, 2003). We encourage future research to further explore the consequences of off-job hassles for individuals. Taken together, in contrast to the general consideration of recovery-a typical focus of past research — our study advocates greater attention to employees' varied experiences during their off-job time.

Our study also speaks to the importance of considering time-frame issues (e.g., weekdays, weekends, and vacations) of off-job experiences. Fritz, Sonnentag, et al. (2010) found that off-job relaxation during the weekend positively relate to both low- and highactivated positive affect during the following workweek, and Binnewies et al. (2010) show 
that off-job relaxation and detachment, rather than mastery, during the weekend predict personal initiative during the following workweek. The inconsistency between the findings of studies using the time frame of weekdays, such as the current study and Sonnentag et al. (2008), and those using the time frame of weekends (e.g., Binnewies et al., 2010; Fritz, Sonnentag, et al., 2010) suggest that off-job experiences likely unfold differently across time. That is to say, the outcomes of off-job experiences could be different on a weekday, weekend, or during a vacation. Researchers thus should be aware of and consider such time-frame issues, providing a more holistic picture of the effects of off-job experiences on individuals.

Moreover, we contribute to the proactivity literature by testing the model of proactive motivation. This model proposes three key motivational states (can do, reason to, and energized to motivations) that stimulate proactive behavior (Parker et al., 2010). Although the three processes have been examined in previous studies (see Bindl \& Parker, 2010), our work is the first, to our knowledge, to test the three mechanisms simultaneously in one model. Our findings suggest that all three motivational states (i.e., can do, reason to, and energized to motivations) are critical for employee proactivity. Furthermore, we provide evidence that high- rather than low-activated positive affect is associated with proactive behavior. This finding speaks to the importance of distinguishing between low and high activation in future affect and recovery research. A general positive affect construct would have masked the nonsignificant linkage between low-activated positive affect and proactivity. We thus encourage researchers to adopt the model of proactive motivation as a theoretical framework to explore the short-term processes of daily proactive behavior and broaden our understanding of the nature of momentary proactive behavior.

Further, we advance the proactivity and recovery literatures by exploring the daylevel predictors of proactive behavior associated with employees' off-job experiences. Previous studies suggest that when employees experience recovery after work, they are more 
likely to attain beneficial outcomes, such as decreased emotional exhaustion and higher proactive initiative (e.g., Demerouti et al., 2009; Fritz, Yankelevich, et al., 2010; Sonnentag, 2003). Unfortunately, these studies have not considered the possibility that employees' participation in various types of off-job experiences could have different effects on proactivity the next workday (Bennett et al., 2016). By investigating specific types of daily off-job experience (i.e., relaxation, detachment, mastery, agency, and hassles), we show that certain off-job experiences are more closely linked to future employee proactive behavior. Off-job relaxation and detachment do little to facilitate next-day proactivity, whereas off-job mastery and agency relate positively, and off-job hassles relate negatively, to proactivity.

Finally, our study expands research on the relationship between employees' off-job experiences and work-related outcomes by exploring the effect of their hassle experiences at home during the evening. By focusing solely on positive experiences during off-job time (e.g.,

relaxation, detachment, mastery, and agency), previous studies have overlooked negative experiences common to daily life. We thus offer a balanced view of off-job experiences by incorporating both positive and negative experiences. Our findings demonstrate that employees' off-job hassles during the evening negatively relate to next-day proactivity. Therefore, it is imperative to account for the effects of negative experiences at home, in that such experiences may offset the benefits produced by other rewarding experiences. Our study contributes to extant literature by providing a clear indication that employees' negative offjob experiences exert significant influence on their work behaviors.

\section{Practical Implications}

Practically, our research highlights the importance of employees' evening off-job experiences in their next-day proactivity. Our findings suggest that engaging in activities associated with mastery or agentic experiences promotes next-day proactive behavior, whereas having relaxing experiences or detaching from work relates only to feelings of 
serenity that do not affect proactivity. Off-job mastery can include picking up a new hobby, volunteering, or learning a new skill. It is also important for employees to feel as if they have autonomous control over decisions about which activities to engage in at night. These conditions relate to increased personal confidence in capabilities; they replenish resources by providing energy and a sense of control that carries over to work the next morning. When employees experience hassles in the evening, they may need to deliberately involve themselves in more beneficial experiences to counterbalance the negative effect of off-job hassles on energy levels, which might help them perform proactively at work. Employees should be aware that what they do during the evening matters to their work proactivity the next day. It is also important to note that, irrespective of any effect on proactivity at work, off-job mastery builds, and off-job hassles diminish, one's next-morning high-activated positive affect, which is a desirable and gratifying affective state for individuals.

Since proactive behavior has important implications for organizations (Crant, 2000), managers should be aware that a variety of factors can predict employee proactive behavior. Our study underscores the role of employee off-job experiences in daily proactive behavior, which managers could leverage to enhance employee proactivity. For example, organizations could provide workshops or seminars to educate employees about recovery and enhance their understanding of the relationship between how they spend their off-job time and proactivity at work. Particularly, our study identifies high-activated positive affect (energized to motivation), role breadth self-efficacy (can do motivation), and desire for control (reason to motivation) as motivational states that link off-job experiences to daily proactive behavior, and the three motivational states are predicted differently by varying types of off-job experiences. Therefore, trainers or facilitators in organizational workshops or seminars should be well aware of, as well as respect, employees' diverse off-job experiences and clarify how such off-job experiences stimulate or hinder employee proactive behavior through distinct 
motivations. Managers might also take measures to help employees cope with negative experiences that occur during evening hours, such as strengthening their sense of control at work (e.g., Ohly \& Fritz, 2010) or uplifting their positive affective experiences during the workday (e.g., Bissing-Olson et al., 2013; Fay \& Sonnentag, 2012), to minimize the detrimental effect of such experiences on employee proactivity. Furthermore, managers and organizations should acknowledge and accept that employees' proactive behavior fluctuates from day to day (e.g., Fay \& Sonnentag, 2012; Ohly \& Fritz, 2010; Sonnentag, 2003). Such knowledge contributes to more reasonable expectations of employees' proactive behavior, enabling managers to be better equipped to respond to an employee's increased or reduced proactivity and to guide employees toward proactivity.

\section{Limitations and Future Research Directions}

Our study has several limitations that should be acknowledged, which suggest directions for future research. First, we could not firmly draw conclusions of causality given the self-reported data for all the key variables in our model. Our research design and data analyses, however, may help alleviate this concern. We collected data at three time points per day, a recommended technique to minimize common method variance (Johnson, Rosen, \& Djurdjevic, 2011). We also group-mean centered all daily variables and controlled for previous-day proactive behavior in our data analyses to make the test more rigorous. Moreover, as mentioned in the Results section, one of our supplemental analyses shows that employees' daily proactive behavior did not significantly relate to their off-job experiences during the evening of the same day (reverse causal paths). Nevertheless, future studies are still needed to support claims of causality.

Second, Bennett et al. (2016) note that employees may undergo various off-job experiences simultaneously, but we examined employees' off-job experiences in isolation. Thus, continued research could examine the effects of a combination of off-job experiences 
on daily proactivity. Also, it is possible that engaging in one type of off-job activity might result in the simultaneous experience of two or more recovery experiences. It would be important for future research to explore how distinct off-job activities predict recovery experiences and in turn affect individuals. Moreover, although off-job mastery has been shown to be beneficial to employees in terms of improved positive affect and higher life satisfaction (e.g., Sonnentag, 2001; Sonnentag \& Fritz, 2007), it is possible that continuous engagement in mastery activities might drain individuals over the long term if substantial resources are invested, which could be an important future research direction.

Third, our study focuses on positive affect while controlling for negative affect. However, negative affect also potentially relates to proactive behavior (e.g., Parker et al., 2010). Low-activated negative affect (e.g., hopelessness) likely broadens individuals' attentional focus and increase their rumination which can stimulate proactive envisioning (e.g., Bindl et al., 2012; Martin \& Tesser, 1996) albeit not proactive action (Bindl et al., 2012). High-activated negative affect, especially anger and frustration, likely prompt proactive behavior to bring about changes in order to reduce the negative emotions, but such feelings also narrow individuals' attentional focus (Gable \& Harmon-Jones, 2010; Parker et al., 2010), which might affect the type of proactivity introduced and/or the way it is implemented. It is thus intriguing to distinguish the effects and contingencies of affect, considering both activation and valence, on employee proactivity. We therefore encourage researchers to consider in greater depth the role of negative affect in future research.

Fourth, our study provides little insight regarding the contingencies of our model. While our focus was specifically on how the five types of off-job experiences relate to nextworkday proactive behavior, it is important for researchers to pursue this research avenue. The different effects of off-job experiences are likely contingent on personal traits or situational factors. For example, the negative effect of off-job hassles on daily proactivity 
might be amplified for neurotic employees, since those individuals tend to experience more negative emotions and perceive more daily stressors (Lanaj, Johnson, \& Lee, 2016).

The final issue concerns the appropriate interpretation of the magnitude of our seemingly small effects and the practical significance of such effects. While our research design covers quite a long time-lag, including sleep, working hours, and weekends, a corresponding limitation of such a design could be smaller effects (Trougakos, Beal, Green, \& Weiss, 2008). It should be noted, however, that small effects found at the daily level have the potential to generate large effects at higher levels of analysis (Martel, Lane, \& Emrich, 1996; Yeaton \& Sechrest, 1981) and can accumulate over time to become large effects (Abelson, 1985). Relatively small significant effects can therefore reflect important consequences of off-job experiences on next-day proactive behaviors.

\section{Conclusion}

The critical importance of rest has long been acknowledged, as indicated by the opening quotation from Hemingway. But, what sort of rest is best? Employees engage in a variety of activities during off-job time that involve both positive and negative experiences. Adopting a motivation perspective of these employee off-job experiences, we found that some types of off-job experiences predict employee daily proactive behavior, while others do not. Off-job mastery and off-job agency positively relate to proactivity, while off-job hassles negatively relate to proactivity, through distinct motivational processes. By integrating proactive motivations with employee off-job experiences, our research advances extant literature by identifying the day-level predictors of daily proactive behavior, clarifying the different effects of off-job experiences on employee proactivity, and examining the different motivational mechanisms through which each type of off-job experience is associated with daily proactive behavior. 


\section{References}

Abelson, R. P. (1985). A variance explanation paradox: When a little is a lot. Psychological Bulletin, 97, 128-132. https://doi.org/10.1037//0033-2909.97.1.129

Aiken, L. S., \& West, S. G. (1991). Multiple regression: Testing and interpreting interactions. Newbury Park, CA: Sage.

Ashford, S. J., \& Black, J. S. (1996). Proactivity during organizational entry: The role of desire for control. Journal of Applied Psychology, 81, 199-214. https://doi.org/10.1037//0021-9010.81.2.199

Axtell, C. M., Holman, D. J., Unsworth, K. L., Wall, T. D., Waterson, P. E., \& Harrington, E. (2000). Shopfloor innovation: Facilitating the suggestion and implementation of ideas. Journal of Occupational and Organizational Psychology, 73, 265-285. https://doi.org/10.1348/096317900167029

Bandura, A. (1997). Self-efficacy: The exercise of control. New York: Freeman.

Bateman, T. S., \& Crant, J. M. (1993). The proactive component of organizational behavior: A measure and correlates. Journal of Organizational Behavior, 14, 103-118. https://doi.org/10.1002/job.4030140202

Baumeister, R. F., Bratslavsky, E., Finkenauer, C., \& Vohs, K. D. (2001). Bad is stronger than the good. Review of General Psychology, 4, 323-370. https://doi.org/10.1037/10892680.5.4.323

Beal, D. J., \& Weiss, H. M. (2003). Methods of ecological momentary assessment in organizational research. Organizational Research Methods, 6, 440-464. https://doi.org/10.1177/1094428103257361

Bennett, A. A., Gabriel, A. S., Calderwood, C., Dahling, J. J., \& Trougakos, J. P. (2016). Better together? Examining profiles of employee recovery experiences. Journal of Applied Psychology, 101, 1635-1654. https://doi.org/10.1037/ap10000157

Benson, H. (1975). The relaxation response. New York: Morrow. 
Bindl, U. K., \& Parker, S. K. (2010). Proactive work behavior: Forward-thinking and changeoriented action in organizations. In S. Zedeck (Ed.), APA handbook of industrial and organizational psychology (Vol. 2, pp. 567-598). Washington, DC: American Psychological Association.

Bindl, U. K., Parker, S. K., Totterdell, P., \& Hagger-Johnson, G. (2012). Fuel of the selfstarter: How mood relates to proactive goal regulation. Journal of Applied Psychology, 97, 134-150. https://doi.org/10.1037/a0024368

Binnewies, C., Sonnentag, S., \& Mojza, E. J. (2009). Daily performance at work: Feeling recovered in the morning as a predictor of day-level job performance. Journal of Organizational Behavior, 30, 67-93. https://doi.org/10.1002/job.541

Binnewies, C., Sonnentag, S., \& Mojza, E. J. (2010). Recovery during the weekend and fluctuations in weekly job performance: A week-level study examining intraindividual relationships. Journal of Occupational and Organizational Psychology, 83, 419-441. https://doi.org/10.1348/096317909x418049

Bissing-Olson, M. J., Iyer, A., Fielding, K. S., \& Zacher, H. (2013). Relationships between daily affect and pro-environmental behavior at work: The moderating role of proenvironmental attitude. Journal of Organizational Behavior, 34, 156-175. https://doi.org/10.1002/job.1788

Bolger, N., DeLongis, A., Kessler, R. C., \& Schilling, E. A. (1989). Effects of daily stress on negative mood. Journal of Personality and Social Psychology, 57, 808-818. https://doi.org/10.1037//0022-3514.57.5.808

Brehm, J. W. (1999). The intensity of emotion. Personality and Social Psychology Review, 3, 2-22. https://doi.org/10.1207/s15327957pspr0301_1

Brislin, R., Lonner, W. J., \& Thorndike, R. (1973). Cross-cultural research methods. New York, NY: Wiley.

Brosschot, J. F., Gerin, W., \& Thayer, J. F. (2006). The perseverative cognition hypothesis: A 
review of worry, prolonged stress-related physiological activation, and health. Journal of Psychosomatic Research, 60, 113-124.

https://doi.org/10.1016/j.jpsychores.2005.06.074

Bryk, A. S., \& Raudenbush, S. W. (1992). Hierarchical linear models for social and behavioural research: Applications and data analysis methods. Newbury Park, CA: Sage.

Burger, J. M. (1985). Desire for control and achievement-related behaviors. Journal of Personality and Social Psychology, 48, 1520-1533. https://doi.org/10.1037//00223514.48.6.1520

Burger, J. M., \& Cooper, H. M. (1979). The desirability of control. Motivation and Emotion, 3, 381-393. https://doi.org/10.1007/bf00994052

Cangiano, F., \& Parker, S. K. (2016). Proactivity for mental health and well-being. In S. Clarke, T. M. Probst, F. Guldenmund \& J. Passmore (Eds.), The Wiley Blackwell handbook of the psychology of occupational safety and workplace health (1st ed., pp. 228-250). Chichester, United Kingdom: Wiley, Ltd.

Crant, J. M. (2000). Proactive behavior in organizations. Journal of Management, 26, 435462. https://doi.org/10.1016/s0149-2063(00)00044-1

Deci, E. L., \& Ryan, R. M. (2000). The "what" and "why" of goal pursuits: Human needs and the self-determination of behavior. Psychological Inquiry, 11, 227-268. https://doi.org/10.1207/s15327965pli1104_01

Demerouti, E., Bakker, A., Geurts, S., \& Taris, T. (2009). Daily recovery from work-related effort during non-work time. In S. Sonnentag, P. L. Perrrewé \& D. C. Ganster (Eds.), Research in occupational stress and well-being (Vol. 7, pp. 85-123). Oxford, U.K.: JAI Press.

Enders, C. K., \& Tofighi, D. (2007). Centering predictor variables in cross-sectional multilevel models: A new look at an old issue. Psychological Methods, 12, 121-138. 
https://doi.org/10.1037/1082-989x.12.2.121

Etzion, D., Eden, D., \& Lapidot, Y. (1998). Relief from job stressors and burnout: Reserve service as a respite. Journal of Applied Psychology, 83, 577-585. https://doi.org/10.1037//0021-9010.83.4.577

Fay, D., \& Sonnentag, S. (2012). Within-person fluctuations of proactive behavior: How affect and experienced competence regulate work behavior. Human Performance, 25, 72-93. https://doi.org/10.1080/08959285.2011.631647

Fredrickson, B. L. (1998). What good are positive emotions? Review of General Psychology, 2, 300-319. https://doi.org/10.1037//1089-2680.2.3.300

Fredrickson, B. L. (2000). Cultivating positive emotions to optimize health and well-being. Prevention \& Treatment, 3, 1-25. https://doi.org/10.1037//1522-3736.3.1.31a

Frese, M., \& Fay, D. (2001). Personal initiative (PI): An active performance concept for work in the 21st century. Research in Organizational Behavior, 23, 133-187. https://doi.org/10.1016/s0191-3085(01)23005-6

Frese, M., Krauss, S. I., Keith, N. K., Escher, S., Grabarkiewicz, R., Luneng, S. T., Heers, C., Unger, J., \& Friedrich, C. (2007). Business owners' action planning and its relationship to business success in three African countries. Journal of Applied Psychology, 92, 1481-1498. https://doi.org/10.1037/0021-9010.92.6.1481

Frijda, N. H. (1986). The emotions: Studies in emotion and social interaction. New York: Cambridge University Press.

Fritz, C., \& Sonnentag, S. (2005). Recovery, health, and job performance: Effects of weekend experiences. Journal of Occupational Health Psychology, 10, 187-199. https://doi.org/10.1037/1076-8998.10.3.187

Fritz, C., \& Sonnentag, S. (2009). Antecedents of day-level proactive behavior: A look at job stressors and positive affect during the workday. Journal of Management, 35, 94-111. https://doi.org/10.1177/0149206307308911 
Fritz, C., Sonnentag, S., Spector, P. E., \& McInroe, J. A. (2010). The weekend matters: Relationships between stress recovery and affective experiences. Journal of Organizational Behavior, 31, 1137-1162. https://doi.org/10.1002/job.672

Fritz, C., Yankelevich, M., Zarubin, A., \& Barger, P. (2010). Happy, healthy, and productive: The role of detachment from work during nonwork time. Journal of Applied Psychology, 95, 977-983. https://doi.org/10.1037/a0019462

Gable, P., \& Harmon-Jones, E. (2010). The blues broaden, but the nasty narrows: Attentional consequences of negative affects low and high in motivational intensity. Psychological Science, 21, 211-215. https://doi.org/10.1177/0956797609359622

Gallo, L. C., Bogart, L. M., Vranceanu, A. M., \& Matthews, K. A. (2005). Socioeconomic status, resources, psychological experiences, and emotional responses: A test of the reserve capacity model. Journal of Personality and Social Psychology, 88, 386-399. https://doi.org/10.1037/0022-3514.88.2.386

Geldhof, G. J., Preacher, K. J., \& Zyphur, M. J. (2014). Reliability estimation in a multilevel confirmatory factor analysis framework. Psychological Methods, 19, 72-91. https://doi.org/10.1037/a0032138

Gist, M. E., \& Mitchell, T. R. (1992). Self-efficacy: A theoretical analysis of its determinants and malleability. Academy of Management Review, 17, 183-211. https://doi.org/10.2307/258770

Grant, A. M., \& Ashford, S. J. (2008). The dynamics of proactivity at work. Research in Organizational Behavior, 28, 3-34. https://doi.org/10.1016/j.riob.2008.04.002

Grant, A. M., Parker, S., \& Collins, C. (2009). Getting credit for proactive behavior: Supervisors reactions depend on what you value and how you feel. Personnel Psychology, 62, 31-55. https://doi.org/10.1111/j.1744-6570.2008.01128.x

Griffin, M. A., Neal, A., \& Parker, S. K. (2007). A new model of work role performance: Positive behavior in uncertain and interdependent contexts. Academy of Management 
Journal, 50, 327-347. https://doi.org/10.5465/amj.2007.24634438

Grossman, P., Niemann, L., Schmidt, S., \& Walach, H. (2004). Mindfulness-based stress reduction and health benefits: A meta-analysis. Journal of Psychosomatic Research, 57, 35-43. https://doi.org/10.1016/s0022-3999(03)00573-7

Hobfoll, S. E. (1989). Conservation of resources: A new attempt at conceptualizing stress. American Psychologist, 44, 513-524. https://doi.org/10.1037/0003-066x.44.3.513 Hobfoll, S. E. (1998). Stress, culture, and community: The psychology and philosophy of stress. New York, NY: Plenum Press.

Hobfoll, S. E. \& Shirom, A. (2001). Conservation of resources theory: Applications to stress and management in the workplace. In R. T. Golembiewski (Ed.), Handbook of Organizational Behavior (pp. 57-80). New York: Marcel Dekker.

Hofmann, S. A., Griffin, M. A., \& Gavin, M. B. (2000). The application of hierarchical linear modeling to organizational research. In K. Klein \& S. Kozlowski (Eds.), Multilevel theory, research, and methods in organizations: Foundations, extensions, and new directions (pp. 75-170). San Francisco, CA: Jossey-Bass.

Isen, A. M. (1999). On the relationship between affect and creative problem solving. In S. Russ (Ed.), Affect, creative experience, and psychological adjustment (pp. 3-17). Philadelphia: Taylor \& Francis.

Jacobson, E. (1938). Progressive relaxation. Chicago: University of Chicago Press.

Johnson, R. E., Rosen, C. C., \& Djurdjevic, E. (2011). Assessing the impact of common method variance on higher-order multidimensional constructs. Journal of Applied Psychology, 96, 744-761. https://doi.org/10.1037/a0021504

Lanaj, K., Johnson, R. E., \& Barnes, C. M. (2014). Beginning the workday yet already depleted? Consequences of late-night smartphone use and sleep. Organizational Behavior and Human Decision Processes, 124, 11-23.

https://doi.org/10.1016/j.obhdp.2014.01.001 
Lanaj, K., Johnson, R. E., \& Lee, S. M. (2016). Benefits of transformational behaviors for leaders: A daily investigation of leader behaviors and need fulfillment. Journal of Applied Psychology, 101, 237-251. https://doi.org/10.1037/ap10000052

Lazarus, R. S. (1991). Emotion and adaptation. New York: Oxford University Press.

Lepore, S. J., \& Evans, G. W. (1996). Coping with multiple stressors in the environment. In M. Zeidner \& N. Endler (Eds.), Handbook of coping: Theory, research and applications (pp. 350-377). New York: Wiley.

Liu, J., Wang, H., Hui, C., \& Lee, C. (2012). Psychological ownership: How having control matters. Journal of Management Studies, 49, 869-895. https://doi.org/10.1111/j.14676486.2011.01028.x

Mandler, G. (1984). Mind and body. New York: Norton.

Martell, R. F., Lane, D. M., \& Emrich, C. (1996). Male female differences: A computer simulation. American Psychologist, 51, 157-158. https://doi.org/10.1037//0003$066 x .51 .2 .157$

Martin, L. L., \& Tesser, A. (1996). Some ruminative thoughts. In J. R. S. Wyer (Ed.), Advances in social cognition (Vol. 9, pp. 1-47). Mahwah, NJ: Erlbaum.

Meijman, T. F., \& Mulder, G. (1998). Psychological aspects of workload. In P. J. D. Drenth \& H. Thierry (Eds.), Handbook of work and organizational psychology (pp. 5-33). Hove, England: Psychology Press.

Nicholls, J. G. (1984). Achievement motivation: Conceptions of ability, subjective experience, task choice, and performance. Psychological Review, 91, 328-346. https://doi.org/10.1037//0033-295x.91.3.328

Ohly, S., \& Fritz, C. (2010). Work characteristics, challenge appraisal, creativity, and proactive behavior: A multi-level study. Journal of Organizational Behavior, 31, 543565. https://doi.org/10.1002/job.633

Parker, S. K. (1998). Enhancing role breadth self-efficacy: The roles of job enrichment and 
other organizational interventions. Journal of Applied Psychology, 83, 835-852. https://doi.org/10.1037/0021-9010.83.6.835

Parker, S. K., Bindl, U. K., \& Strauss, K. (2010). Making things happen: A model of proactive motivation. Journal of Management, 36, 827-856. https://doi.org/10.1177/0149206310363732

Parker, S. K., \& Collins, C. G. (2010). Taking stock: Integrating and differentiating multiple proactive behaviors. Journal of Management, 36, 633-662. https://doi.org/10.1177/0149206310363732

Parker, S. K., Collins, C. G., \& Grant, A. (2008, April). The role of positive affect in making things happen. Annual SIOP Conference. San Francisco, USA.

Parker, S. K., Williams, H. M., \& Turner, N. (2006). Modeling the antecedents of proactive behavior at work. Journal of Applied Psychology, 91, 636-652. https://doi.org/10.1037/0021-9010.91.3.636

Pelletier, C. L. (2004). The effect of music on decreasing arousal due to stress: A metaanalysis. Journal of Music Therapy, 41, 192-214. https://doi.org/10.1093/jmt/41.3.192

Peterson, C. (1999). Personal control and well-being. In D. Kahneman \& E. Diener (Eds.), Well-being: The foundations of hedonic psychology (pp. 288-301). New York: Russell Sage Foundation.

Phan, H. P. (2014). An integrated framework involving enactive learning experiences, mastery goals, and academic engagement-disengagement: A causal modeling examination. European Journal of Psychology, 10, 41-66. https://doi.org/10.5964/ejop.v10i1.680

Poldrack, R. A., Prabhakaran, V., Seger, C. A., \& Gabrieli, J. D. (1999). Striatal activation during acquisition of a cognitive skill. Neuropsychology, 13, 564-574. https://doi.org/10.1037//0894-4105.13.4.564

Preacher, K. J., Zyphur, M. J., \& Zhang, Z. (2010). A general multilevel SEM framework for 
assessing multilevel mediation. Psychological Methods, 15, 209-233. https://doi.org/10.1037/a0020141

Quinn, R. W., Spreitzer, G. M., \& Lam, C. F. (2012). Building a sustainable model of human energy in organizations: Exploring the critical role of resources. Academy of Management Annals, 6, 337-396. https://doi.org/10.1080/19416520.2012.676762

Ramsey, A. T., \& Etcheverry, P. E. (2013). Aligning task control with desire for control: Implications for performance. Basic \& Applied Social Psychology, 35, 467-476. https://doi.org/10.1080/01973533.2013.823617

Reis, H. T., Sheldon, K. M., Gable, S. L., Roscoe, J., \& Ryan, R. M. (2000). Daily well-being: The role of autonomy, competence, and relatedness. Personality and Social Psychology Bulletin, 26, 419-435. https://doi.org/10.1177/0146167200266002

Ross, C. E., \& Broh, B. A. (2000). The roles of self-esteem and the sense of personal control in the academic achievement process. Sociology of Education, 73, 270-284. https://doi.org/10.2307/2673234

Russell, J. A. (1980). A circumplex model of affect. Journal of Personality and Social Psychology, 39, 1161-1178. https://doi.org/10.1037/h0077714

Russell, J. A. (2003). Core affect and the psychological construction of emotion. Psychological Review, 110, 145-172. https://doi.org/10.1037//0033-295x.110.1.145

Ryan, R. M., \& Deci, E. L. (2008). From ego depletion to vitality: Theory and findings concerning the facilitation of energy available to the self. Social and Personality Psychology Compass, 2, 702-717. https://doi.org/10.1111/j.1751-9004.2008.00098.x

Schwarzer, R. (1992). Self-efficacy: Thought control of action. Washington, DC: Hemisphere.

Selig, J. P., \& Preacher, K. J. (2008). Monte Carlo method for assessing mediation: An interactive tool for creating confidence intervals for indirect effects [Computer software]. Available from http://quantpsy.org.

Sheldon, K. M., \& Houser-Marko, L. (2001). Self-concordance, goal attainment, and the 
pursuit of happiness: Can there be an upward spiral? Journal of Personality and Social Psychology, 80, 152-165. https://doi.org/10.1037//0022-3514.80.1.152

Singer, J. D., \& Willett, J. B. (2003). Applied longitudinal data analysis: Modeling change and event occurrence. New York: Oxford University Press.

Skinner, E. A. (1996). A guide to constructs of control. Journal of Personality and Social Psychology, 71, 549-570. https://doi.org/10.1037//0022-3514.71.3.549

Sonnentag, S. (2001). Work, recovery activities, and individual well-being: A diary study. Journal of Occupational Health Psychology, 6, 196-210. https://doi.org/10.1037//1076-8998.6.3.196

Sonnentag, S. (2003). Recovery, work engagement, and proactive behavior: A new look at the interface between nonwork and work. Journal of Applied Psychology, 88, 518-528. https://doi.org/10.1037/0021-9010.88.3.518

Sonnentag, S., Binnewies, C., \& Mojza, E. J. (2008). “Did you have a nice evening?” A daylevel study on recovery experiences, sleep, and affect. Journal of Applied Psychology, 93, 674-684. https://doi.org/10.1037/0021-9010.93.3.674

Sonnentag, S., \& Fritz, C. (2007). The Recovery Experience Questionnaire: Development and validation of a measure for assessing recuperation and unwinding from work. Journal of Occupational Health Psychology, 12, 204-221. https://doi.org/10.1037/1076-8998.12.3.204

Sonnentag, S., \& Kühnel, J. (2016). Coming back to work in the morning: Psychological detachment and reattachment as predictors of work engagement. Journal of Occupational Health Psychology, 21, 379-390. https://doi.org/10.1037/ocp0000020

Sonnentag, S., \& Starzyk, A. (2015). Perceived prosocial impact, perceived situational constraints, and proactive work behavior: Looking at two distinct affective pathways. Journal of Organizational Behavior, 36, 806-824. https://doi.org/10.1002/job.2005

Stone, A. A., Kennedy-Moore, E., \& Neale, J. M. (1995). Association between daily coping 
and end-of-day mood. Health Psychology, 14, 341-349.

https://doi.org/10.1037//0278-6133.14.4.341

Strauss, K., Parker, S. K., \& O’Shea, D. (2017). When does proactivity have a cost?

Motivation at work moderates the effects of proactive work behavior on employee job strain. Journal of Vocational Behavior, 100, 15-26.

https://doi.org/10.1016/j.jvb.2017.02.001

Taris, T. W., \& Kompier, M. A. J. (2005). Job characteristics and learning behavior. In P. L. Perrewe \& D. C. Ganster (Eds.), Research in occupational stress and well-being: Exploring interpersonal dynamics (pp. 127-166). Amsterdam: JAI Press.

Trougakos, J. P., Beal, D. J., Green, S. G., \& Weiss, H. M. (2008). Making the break count: An episodic examination of recovery activities, emotional experiences, and positive affective displays. Academy of Management Journal, 51, 131-146. https://doi.org/10.5465/amj.2008.30764063

Trougakos, J. P., Hideg, I., Cheng, B. H., \& Beal, D. J. (2014). Lunch breaks unpacked: The role of autonomy as a moderator of recovery during lunch. Academy of Management Journal, 57, 405-421. https://doi.org/10.5465/amj.2011.1072

Van der Klink, J. J., Blonk, R. W., Schene, A. H., \& Van Dijk, F. J. (2001). The benefits of interventions for work-related stress. American Journal of Public Health, 91, 270-276. https://doi.org/10.2105/ajph.91.2.270

van Woerkom, M., Bakker, A. B., \& Nishii, L. H. (2016). Accumulative job demands and support for strength use: Fine-tuning the job demands-resources model using conservation of resources theory. Journal of Applied Psychology, 101, 141-150. https://doi.org/10.1037/ap10000033

Warr, P. B. (1990). The measurement of well-being and other aspects of mental health. Journal of Occupational Psychology, 63, 193-210. https://doi.org/10.1111/j.20448325.1990.tb00521.x 
Watson, D., Wiese, D., Vaidya, J., \& Tellegen, A. (1999). The two general activation systems of affect: Structural findings, evolutionary considerations and psychobiological evidence. Journal of Personality and Social Psychology, 76, 820-838. https://doi.org/10.1037//0022-3514.76.5.820

West, M., \& Rushton, R. (1989). Mismatches in the work-role transitions. Journal of Occupational Psychology, 62, 271-286. https://doi.org/10.1111/j.20448325.1989.tb00500.x

West, S. G., \& Hepworth, J. T. (1991). Statistical issues in the study of temporal data: Daily experiences. Journal of Personality, 59, 609-662. https://doi.org/10.1111/j.14676494.1991.tb00261.x

Yeaton, W, \& Sechrest, L. (1981). Meaningful measures of effect. Journal of Consulting and Clinical Psychology, 49, 766-767. https://doi.org/10.1037//0022-006x.49.5.766

Zohar, D., Tzischinski, O., \& Epstein, R. (2003). Effects of energy availability on immediate and delayed emotional reactions to work events. Journal of Applied Psychology, 88, 1082-1093. https://doi.org/10.1037/0021-9010.88.6.1082 


\section{Table 1}

Percentage of Within-Individual Variance among Daily Variables

\begin{tabular}{cccc}
\hline Variable & Within-Individual Variance $\left(\mathbf{e}^{2}\right)$ & Between-Individual Variance ( $\left.\mathbf{r}^{2}\right)$ & Within-Individual Variance (\%) \\
\hline Off-job mastery & 0.86 & 0.74 & $53.8 \%$ \\
Off-job agency & 0.97 & 0.70 & $58.1 \%$ \\
Off-job hassles & 0.14 & 0.17 & $45.2 \%$ \\
Off-job relaxation & 1.21 & 0.72 & $63.7 \%$ \\
Off-job detachment & 1.44 & 1.01 & $58.8 \%$ \\
High-activated positive affect & 0.50 & 0.62 & $44.6 \%$ \\
Low-activated positive affect & 0.36 & 0.47 & $43.4 \%$ \\
Role breadth self-efficacy & 0.42 & 0.79 & $34.7 \%$ \\
Desire for control & 0.48 & 0.67 & $41.7 \%$ \\
Proactive behavior & 0.64 & 0.92 & $41.0 \%$ \\
\hline
\end{tabular}

Notes. The percentage of variance within individuals was calculated as $\mathrm{e}^{2} /\left(\mathrm{e}^{2}+\mathrm{r}^{2}\right)$. 


\section{Table 2}

Means, Standard Deviations, and Correlations among Study Variables

\begin{tabular}{|c|c|c|c|c|c|c|c|c|c|c|c|c|c|c|c|}
\hline Variables & Mean & $S D$ & 1 & 2 & 3 & 4 & 5 & 6 & 7 & 8 & 9 & 10 & 11 & 12 & 13 \\
\hline 1. Proactive personality & 4.91 & 0.79 & & & & & & & & & & & & & \\
\hline 2. Morning low-activated negative affect & 1.93 & 1.06 & -.02 & & $.69 * * *$ & $-.19 * * *$ & $-.12 * * *$ & .02 & $-.20 * * *$ & $.23 * * *$ & $-.18 * * *$ & $-.20 * * *$ & $-.16^{* * *}$ & -.04 & $.08 * *$ \\
\hline 3. Morning high-activated negative affect & 2.64 & 1.18 & -.14 & $.75 * * *$ & & $-.23 * * *$ & $-.18 * * *$ & -.04 & $-.21 * * *$ & $.12 * * *$ & $-.25 * * *$ & $-.22 * * *$ & $-.19 * * *$ & $-.10 * * *$ & -.02 \\
\hline 4. Previous-evening off-job relaxation & 4.40 & 1.39 & .00 & $-.24 * *$ & $-.30 * * *$ & & $.75 * * *$ & $.05 *$ & $.53 * * *$ & $-.18 * * *$ & $.28 * * *$ & $.08 * *$ & $.12 * * *$ & .01 & -.00 \\
\hline 5. Previous-evening off-job detachment & 3.98 & 1.56 & -.02 & $-.17 *$ & $-.22 * *$ & $.81 * * *$ & & $-.09 * * *$ & $.38 * * *$ & $-.19 * * *$ & $.20 * * *$ & .01 & .03 & $-.06^{*}$ & $-.07 * *$ \\
\hline 6. Previous-evening off-job mastery & 3.58 & 1.27 & $.39 * * *$ & .02 & -.10 & .03 & -.12 & & $.25 * * *$ & $.10 * * *$ & $.14 * * *$ & $.28 * * *$ & $.31 * * *$ & $.23 * * *$ & $.37 * * *$ \\
\hline 7. Previous-evening off-job agency & 4.79 & 1.29 & $.17 *$ & $-.33 * * *$ & $-.30 * * *$ & $.59 * * *$ & $.38 * * *$ & $.26 * * *$ & & $-.11 * * *$ & $.15^{* * *} *$ & $.14 * * *$ & $.30 * * *$ & $.18 * * *$ & $.18 * * *$ \\
\hline 8. Previous-evening off-job hassles & 1.41 & 0.56 & .04 & $.29 * * *$ & .14 & $-.24 * *$ & $-.26 * * *$ & .14 & -.13 & & -.03 & -.01 & -.05 & .01 & $.07 *$ \\
\hline 9. Morning low-activated positive affect & 3.92 & 0.91 & .09 & $-.15^{*}$ & $-.26 * * *$ & $.37 * * *$ & $.29 * * *$ & $.22 * *$ & $.16^{*}$ & -.00 & & $.34 * * *$ & $.18 * * *$ & $.07 * *$ & $.12 * * *$ \\
\hline 10. Morning high-activated positive affect & 4.08 & 1.05 & $.47 * * *$ & $-.15^{*}$ & $-.21 * *$ & .05 & -.05 & $.43 * * *$ & .14 & .05 & $.31 * * *$ & & $.51 * * *$ & $.40 * * *$ & $.42 * * *$ \\
\hline 11. Morning role breadth self-efficacy & 4.33 & 1.10 & $.40 * * *$ & $-.15^{*}$ & $-.22 * *$ & .13 & .01 & $.44 * * *$ & $.38 * * *$ & -.06 & $.17^{*}$ & $.58 * * *$ & & $.60 * * *$ & $.51 * * *$ \\
\hline 12. Morning desire for control & 4.09 & 1.07 & $.39 * * *$ & -.01 & -.10 & -.09 & $-.16^{*}$ & $.37 * * *$ & $.20 * *$ & .04 & .03 & $.51 * * *$ & $.73 * * *$ & & $.42 * * *$ \\
\hline 13. Day-level proactive behavior & 3.37 & 1.22 & $.47 * * *$ & -.01 & -.10 & -.03 & $-.15^{*}$ & $.58 * * *$ & $.27 * * *$ & .12 & $.16^{*}$ & $.59 * * *$ & $.72 * * *$ & $.60 * * *$ & \\
\hline
\end{tabular}

Notes. Means and SDs refer to person-level data. Correlations of the variables aggregated to the person level appear below the diagonal $(N=183)$; within-person correlations appear above the diagonal $(N=1240)$

$* p<.05 . * * p<.01 . * * * p<.001$. 
Table 3

Unstandardized Coefficients from Multilevel Path Analysis Predicting Morning Motivational States and Daily Proactive Behavior

\begin{tabular}{|c|c|c|c|c|c|c|c|c|c|c|c|c|}
\hline \multirow[t]{2}{*}{ Predictors } & \multicolumn{3}{|c|}{$\begin{array}{c}\text { Morning high-activated } \\
\text { positive affect }\end{array}$} & \multicolumn{3}{|c|}{$\begin{array}{c}\text { Morning role breadth } \\
\text { self-efficacy }\end{array}$} & \multicolumn{3}{|c|}{$\begin{array}{c}\text { Morning desire for } \\
\text { control }\end{array}$} & \multicolumn{3}{|c|}{$\begin{array}{c}\text { Morning low-activated } \\
\text { positive affect }\end{array}$} \\
\hline & Estimate & $S E$ & $\mathrm{z}$ & Estimate & $S E$ & $\mathrm{z}$ & Estimate & $S E$ & $\mathrm{z}$ & Estimate & $S E$ & $\mathrm{z}$ \\
\hline \multicolumn{13}{|l|}{ Between level } \\
\hline Intercept & 1.02 & .14 & $7.12 * * *$ & .83 & .21 & $3.90 * * *$ & .96 & .17 & $5.73^{* * *}$ & 1.28 & .35 & $3.68 * * *$ \\
\hline Proactive personality & .21 & .06 & $3.37 * * *$ & .16 & .06 & $2.68 * *$ & .15 & .05 & $2.83 * *$ & .02 & .06 & .31 \\
\hline Residual variance & .24 & .05 & $4.61 * * *$ & .27 & .07 & $3.73 * * *$ & .20 & .06 & $3.21^{* * *}$ & .17 & .04 & $4.07 * * *$ \\
\hline \multicolumn{13}{|l|}{ Within level } \\
\hline Morning low-activated negative affect & -.18 & .05 & $-3.42 * * *$ & -.12 & .05 & $-2.26^{*}$ & -.02 & .03 & -.67 & -.08 & .03 & $-2.43 *$ \\
\hline Morning high-activated negative affect & -.03 & .03 & -1.04 & -.05 & .03 & -1.72 & -.07 & .03 & $-2.17 *$ & -.13 & .03 & $-4.40 * * *$ \\
\hline Previous-day proactive behavior & .07 & .03 & $2.35^{*}$ & .09 & .04 & $2.14^{*}$ & .06 & .03 & $2.01 *$ & .08 & .04 & $2.12 *$ \\
\hline Previous-evening off-job mastery & .06 & .03 & $2.08 *$ & .07 & .04 & $2.02 *$ & .04 & .04 & 1.05 & - & - & - \\
\hline Previous-evening off-job agency & .03 & .04 & .71 & .09 & .03 & $2.75 * *$ & .08 & .03 & $2.71 * *$ & - & - & - \\
\hline Previous-evening off-job hassles & -.09 & .03 & $-2.85 * *$ & - & - & - & - & - & - & -.01 & .05 & -.26 \\
\hline Previous-evening off-job relaxation & - & - & - & - & - & - & - & - & - & .11 & .04 & $2.66^{* *}$ \\
\hline Previous-evening off-job detachment & - & - & - & - & - & - & - & - & - & .02 & .03 & .71 \\
\hline Previous-evening off-job detachment squared & - & - & - & - & - & - & - & - & - & -.03 & .02 & $-2.04 *$ \\
\hline Residual variance & .46 & .06 & $7.42 * * *$ & .51 & .08 & $6.15 * * *$ & .47 & .06 & $7.75^{* * *}$ & .42 & .05 & $8.64 * * *$ \\
\hline \multirow[t]{3}{*}{ Pseudo- $R^{2}$ at Level 1} & .17 & & & .16 & & & .13 & & & .15 & & \\
\hline & \multicolumn{12}{|c|}{ Daily proactive behavior } \\
\hline & \multicolumn{4}{|c|}{ Estimate } & \multicolumn{4}{|c|}{$S E$} & \multicolumn{4}{|c|}{$\mathrm{z}$} \\
\hline \multicolumn{13}{|l|}{ Between level } \\
\hline Intercept & \multicolumn{4}{|c|}{.97} & \multicolumn{4}{|c|}{.11} & \multicolumn{4}{|c|}{$8.81^{* * *}$} \\
\hline Proactive personality & \multicolumn{4}{|c|}{.28} & \multicolumn{4}{|c|}{.07} & \multicolumn{4}{|c|}{$3.89^{* * *}$} \\
\hline Residual variance & \multicolumn{4}{|c|}{.36} & \multicolumn{4}{|c|}{.07} & \multicolumn{4}{|c|}{$5.11 * * *$} \\
\hline \multicolumn{13}{|l|}{ Within level } \\
\hline Morning low-activated negative affect & \multicolumn{4}{|c|}{.05} & \multicolumn{4}{|c|}{.04} & \multicolumn{4}{|c|}{1.32} \\
\hline Morning high-activated negative affect & & & .02 & & & & 5 & & & .45 & & \\
\hline Previous-day proactive behavior & & & .20 & & & & 3 & & & $6.15^{*}$ & & \\
\hline Morning high-activated positive affect & & & .08 & & & & 3 & & & $2.63^{3}$ & & \\
\hline Morning role breadth self-efficacy & & & .09 & & & & 3 & & & $2.81^{*}$ & & \\
\hline Morning desire for control & & & .11 & & & & 4 & & & $2.78^{\circ}$ & & \\
\hline Residual variance & & & .41 & & & & 2 & & & $17.13^{3}$ & & \\
\hline Pseudo- $R^{2}$ at Level 1 & & & .20 & & & & & & & & & \\
\hline
\end{tabular}


Off-Job Experiences

Motivational States

Work Behavior

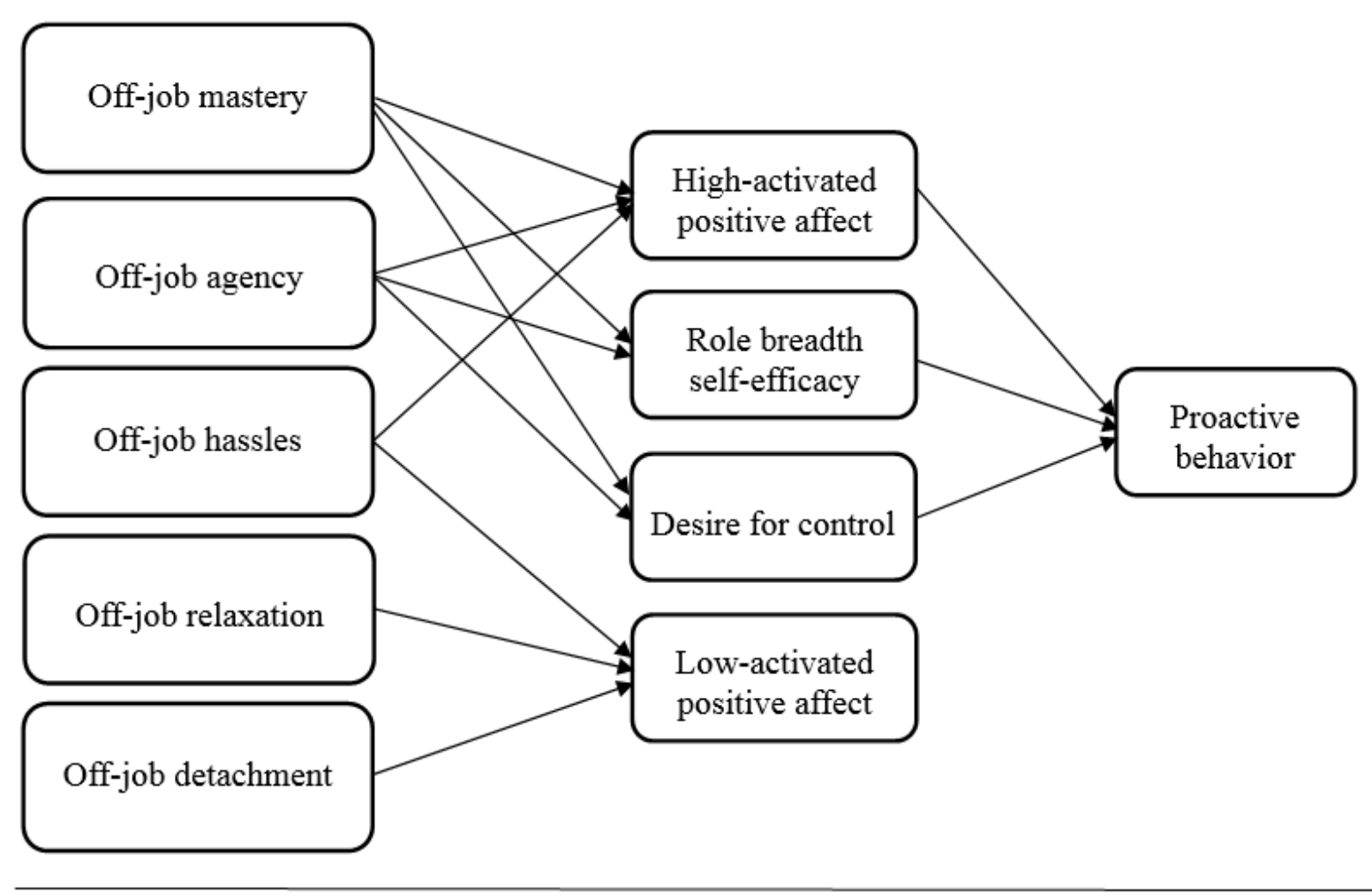

During the previous evening

During the morning

During the workday

Figure 1. Research model. 
Off-Job Experiences

Motivational States

Work Behavior

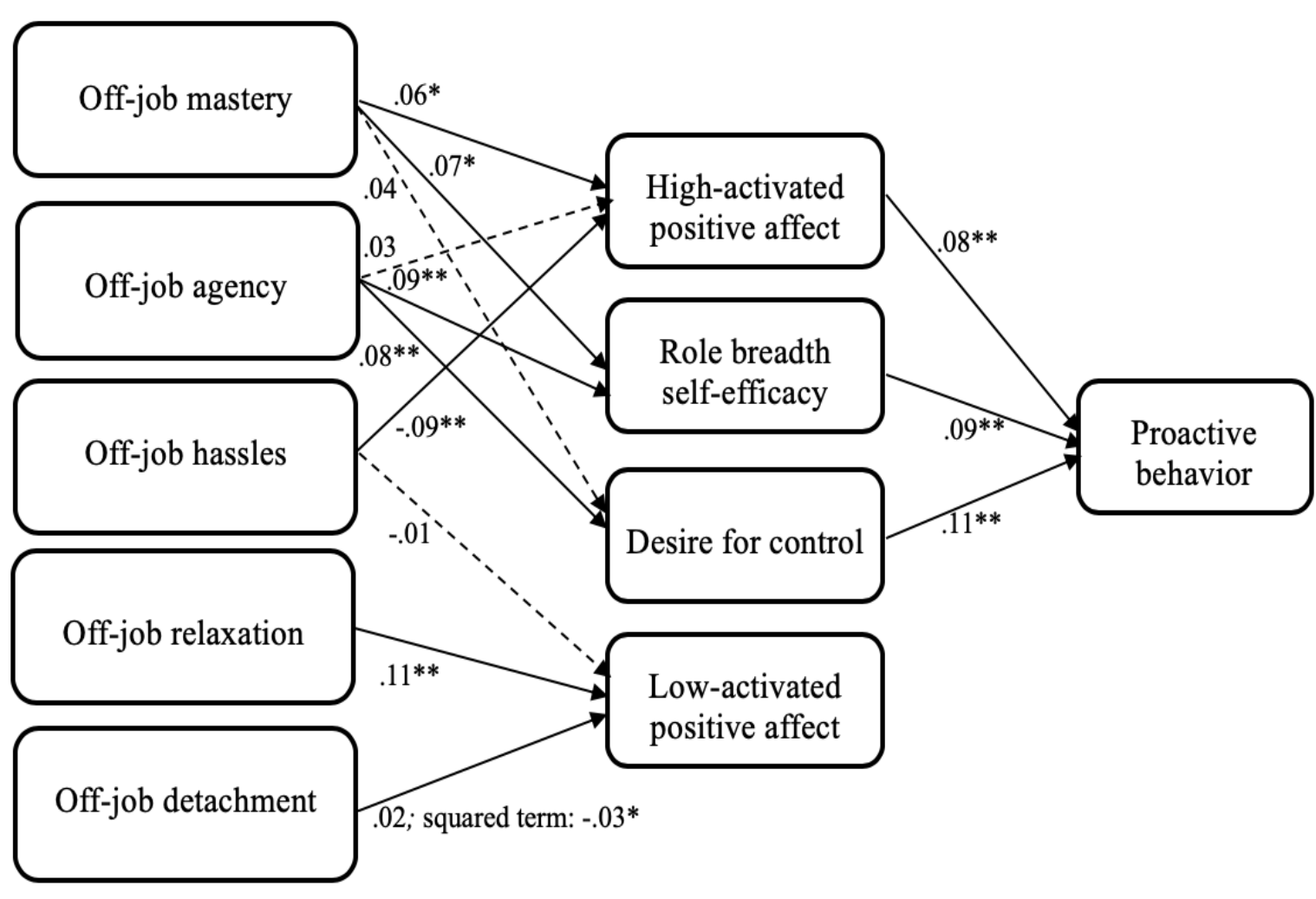

During the previous evening

During the morning

During the workday

Figure 2. Multilevel path analysis results of the research model. Level 1, $N=1240$; level 2, $N=183$. The estimates are unstandardized coefficients. Solid lines refer to hypothesized relationships supported, and dashed lines refer to hypothesized relationships not supported. For clarity, control variables (i.e., proactive personality, morning low-activated and high-activated negative affect, previous-day proactive behavior) are not pictured. $* p<.05 . * * p<.01$. 


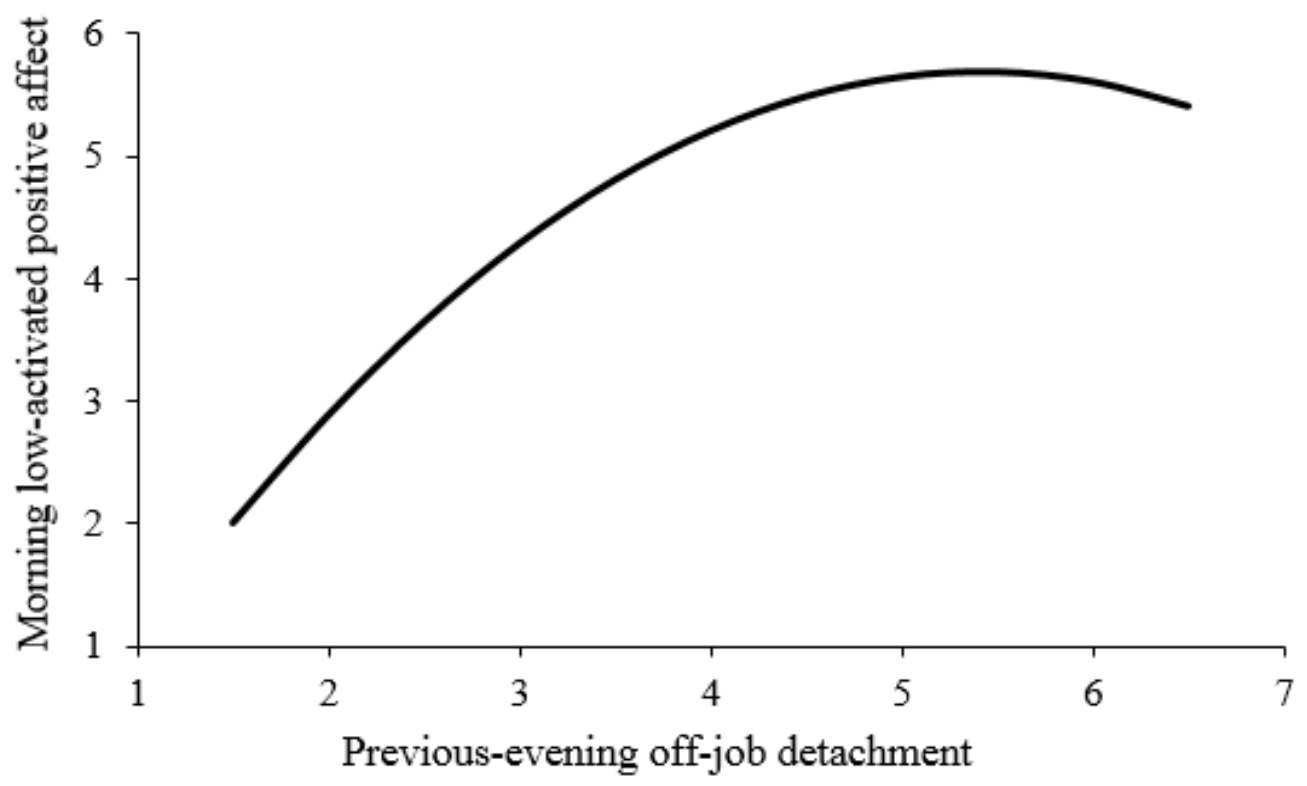

Figure 3. Curvilinear relationship between previous-evening off-job detachment and morning low-activated positive affect. 